\title{
ATLAS DE LOS PTERIDÓFITOS DE LA PENÍNSULA IBÉRICA E ISLAS BALEARES
}

\author{
Juan Carlos MORENO SAIZ ${ }^{*}$, Luciano PATARO ${ }^{1}$ y Santiago PAJARÓN SOTOMAYOR² \\ ${ }^{1}$ Dpto. de Biología (Botánica), Universidad Autónoma de Madrid, C/ Darwin 2, 28049 Madrid. \\ ${ }^{2}$ Dpto. de Biología Vegetal I, Universidad Complutense, C/ José Antonio Novais 2, 28040 Madrid. \\ *Autor para correspondencia: jcarlos.moreno@uam.es
}

RESUMEN. Atlas de los pteridófitos de la Península Ibérica e Islas Baleares. Se han elaborado los mapas de distribución de los licófitos y helechos del suroccidente europeo (Andorra, España continental, Portugal continental e Islas Baleares) empleando la malla UTM de $10 \mathrm{~km}$ de lado. La síntesis corológica incluye citas bibliográficas y fuentes electrónicas georreferenciadas de acceso público para un total de 128 taxones presentes en el territorio.

Palabras clave. Pteridófitos, Lycopodiophyta, Monilophyta, corología, Península Ibérica, Islas Baleares.

ABSTRACT. Atlas of the pteridophytes of the Iberian Peninsula and the Balearic Islands. Distributions of southwest European lycophytes and ferns (Andorra, mainland Spain, mainland Portugal and the Balearic Islands) have been mapped using the UTM grid of $10 \mathrm{~km}$ of side. The chorological compilation includes bibliography and electronic georeferenced sources of public access covering the 128 taxa present in the study area.

Key words. Pteridophytes, Lycopodiophyta, Monilophyta, chorology, Iberian Peninsula, Balearic Islands

\section{INTRODUCCIÓN}

Los pteridófitos, licófitos y helechos, constituyen un grupo parafilético (Pryer et al., 2001, 2004) que sigue no obstante analizándose en común dentro de los estudios de biogeografía histórica o ecológica (Muñoz et al., 2004; Chiarucci et al., 2011). Ello se justifica porque comparten una serie de características biológicas y ecológicas, como el hecho de ser buenos colonizadores al ser sus esporas dispersadas a largas distancias y

Este trabajo ha sido desarrollado en el marco del proyecto "Identificando síndromes de sensibilidad a la fragmentación de hábitats en plantas y aves holárticas" (CGL2013-48768-P) financiado por la de la Dirección General de Investigación Científica y Técnica (MINECO). 
conectar así áreas alejadas (Smith, 1972, 1993; Barrington, 1993; Muñoz et al., 2004). Dicha propiedad, junto a la existencia de reproducción asexual o la resistencia mostrada por esporas o esporocarpos a periodos adversos, hace que las distribuciones de muchos pteridófitos se vean limitadas principalmente por las condiciones ambientales reinantes en cada época y región determinadas (Richard et al., 2000; Bystriakova et al., 2014).

En Europa los estudios biogeográficos sobre este grupo han empleado la base cartográfica que brindó la publicación del volumen inicial del Atlas Florae Europaeae (Jalas \& Suominen, 1972). Trabajos como los de Birks (1976) y Vogel et al. (1999) analizaron los patrones de distribución con el detalle que permitía la malla UTM de $50 \mathrm{~km}$ de lado.

Para la Península Ibérica e Islas Baleares el atlas de Jalas \& Suominen (op. cit.) se reveló pronto incompleto, siendo sustituido por el Atlas de la Pteridoflora Ibérica y Balear de Salvo et al. (1984), más documentado y actualizado aunque con la misma escala. Los ensayos biogeográficos y conservacionistas siguieron usando dichas cuadrículas de 50 $\mathrm{km}$ cuando el área del estudio pteridológico se extendía a todo el suroccidente europeo (Pichi-Sermolli et al., 1988; Márquez et al., 1997; Ferrer Castán \& Vetaas, 2005; Moreno Saiz \& Lobo, 2008).

La cartografía completa de pteridófitos comenzó a emplear una escala más detallada (malla UTM de $10 \mathrm{~km}$ de lado) a partir de estudios regionales (Amaral Franco \& Rocha Afonso, 1983; Sáez, 1997; Carrión Vilches et al., 2000; Belmonte Andújar et al., 2011). El uso de esta unidad geográfica operativa se ha limitado a trabajos con un número reducido de especies ibero-baleáricas o sobre una parte de la geografía (Moreno Saiz et al., 1996; Pausas \& Sáez, 2000).

En los últimos años se ha producido un auge en los estudios y proyectos corológicos sobre la flora ibero-baleárica en general, y sobre la pteridoflora en particular (Cabezudo \& Trigo, 2004). El sesgo muestral por territorios se ha venido reduciendo y la información a dicha escala, o incluso para cuadrículas de $1 \mathrm{~km}$ de lado, se ha hecho accesible en publicaciones y bases de datos electrónicas. Por ello, el objetivo de este trabajo es la elaboración de un atlas con las distribuciones de todos los licófitos y helechos peninsulares y baleáricos que sirva para la realización de estudios básicos y aplicados sobre este grupo de plantas.

\section{METODOLOGÍA}

El área de estudio comprendió el extremo suroccidental europeo, es decir la Península Ibérica (Andorra, España continental y Portugal continental) y las Islas Baleares, totalizando una superficie de $589.292 \mathrm{~km}^{2}$. La malla UTM de $100 \mathrm{~km}^{2}$ en este territorio comprende 6.399 celdas.

Se llevó a cabo una revisión bibliográfica pormenorizada de la literatura florística y corológica aparecida hasta diciembre de 2014. En ella, además de la consulta de monografías y revistas al uso, se incorporaron las citas procedentes de atlas regionales, tanto los elaborados específicamente sobre pteridófitos como los dedicados a la flora vascular general de sus territorios (p.e. Villar et al., 1997; Bolòs, 1998; Segura Zubizarreta et al., 2000). Asimismo, se añadió la información recopilada en diversos mapas corológicos de las revistas Fontqueria y Botanica Complutensis y en la sección de Notas Pteridológicas de Acta Botanica Malacitana.

Por otro lado, se reunió la información almacenada en bases de datos electrónicas georreferenciadas de acceso público. Hasta mayo de 2015 se descargaron las citas corológicas de Anthos, Atlas de la Flora de Aragón, BIOCAT, Flora-On, SITEB, SIVIM $\mathrm{y}$, eventualmente, se hicieron consultas en GBIF y en la Base de Datos de Flora Vascular 
de Castilla y León. Por último, se incorporaron los registros georreferenciados y revisados procedentes del herbario de la Universidad de Málaga (MGC).

Todas las citas se transformaron a CUTMs de $100 \mathrm{~km}^{2}$ y con ellas se construyó una matriz de datos con las presencias/ausencias de los pteridófitos peninsulares y baleáricos. Más tarde, esta base se llevó al sistema de información geográfica ArcGis $10.3 \AA$ y se elaboraron los mapas de todas las especies a la búsqueda de registros erróneos y dudosos.

La propuesta de Castroviejo et al. (1986) en Flora iberica se usó para elaborar el catálogo inicial de pteridófitos ibero-baleáricos, si bien el listado y el esquema taxonómico empleado en este trabajo incorporó actualizaciones procedentes de hallazgos corológicos, revisiones taxonómicas, filogenias moleculares, biología reproductiva, etc. En algún caso se prescindió de la cartografía de subespecies cuya entidad y distribución se halla sujeta a debate. Los mapas del género Marsilea L. se ciñeron a las localidades actuales de sus tres especies autóctonas. En total se reconocieron 122 pteridófitos autóctonos y seis alóctonos de cierta extensión en el área de estudio.

\section{RESULTADOS}

La revisión efectuada permitió construir una base de datos de 31.870 registros únicos sobre la presencia de los diferentes taxones de helechos (112 especies y subespecies) y licófitos (16) reconocidos en el suroccidente europeo (tab. 1). Hasta donde sabemos, se trata de la segunda base de datos pteridológica más nutrida tras la australiana (60.000 registros, cf. Nagalingum et al., 2015), si bien sobre un territorio trece veces menor. Un total de 4.733 cuadrículas contaron con al menos un taxón registrado.

Los pteridófitos, a tenor del muestreo llevado a cabo en el territorio y de la recopilación realizada, se reparten heterogéneamente por la Península y Baleares (fig. 1). No hay citas en buena parte del interior peninsular, particularmente en zonas de ambas mesetas y en tramos de las cuencas de los ríos Ebro, Guadiana y Guadalquivir. Las Islas Baleares y las franjas costeras peninsulares muestran por el contrario una presencia más continua de pteridófitos, aunque son las áreas montañosas las que destacan por su riqueza: eje PirenaicoCantábrico, sierras Béticas y serranía de Algeciras. Los puntos con mayor número de taxones fueron 31TCH13 (47), 30SVG60 (42), 30TXN75 (38), 31TCH12 (38), 31TDG52 (38) y 30STE79 (37) .

La extensión de las distribuciones individuales resultó, como era previsible, de gran heterogeneidad. Frente a taxones ampliamente repartidos como Pteridium aquilinum (L.) Kuhn subsp. aquilinum (1.891 CUTMs), Asplenium ceterach L. (1.779) o Equisetum ramosissimum Desf. (1.502) se situaron en el otro extremo helechos como Asplenium obovatum subsp. protobillotii Herrero, Pajarón \& Prada, Hymenophyllum wilsonii Hook. y Woodsia glabella subsp. pulchella (Bertol.) Á. Löve \& D. Löve, cada uno en una sola celda.

Los mapas de distribución (mapas 1 a 88) que se presentan con este trabajo (fig. 2) constituyen el atlas de distribución completo más reciente y de escala más detallada de los elaborados sobre pteridófitos en el continente europeo.

AGRADECIMIENTOS. L. Pataro agradece a la CAPES por la beca pre-doctoral concedida (proceso número 1192/13-2). Nuestra gratitud a todos aquellos que nos facilitaron información, en particular a los responsables de webs de acceso restringido. A Baltasar Cabezudo por el suministro de la base de datos electrónica del herbario MGC. A los colegas que resolvieron diversas dudas florísticas y taxonómicas con motivo de nuestras consultas: Leopoldo Medina, Llorenç Sáez, Emilio Laguna, Antonio Delgado, Laura Plaza, Emilia Pangua y Luis G. Quintanilla. 
Adiantum capillus-veneris L. (mapa 1)

Anogramma leptophylla (L.) Link (mapa 2)

Asplenium adiantum-nigrum L. (mapa 3)

Asplenium azomanes Rosselló, Cubas \& Rebassa

(mapa 3)

Asplenium balearicum Shivas (mapa 4)

Asplenium billotii F.W. Schultz (mapa 4)

Asplenium celtibericum Rivas Mart. (mapa 5)

Asplenium ceterach L. (mapa 6)

Asplenium csikii Kümmerle \& András. (mapa 7)

Asplenium fontanum (L.) Bernh. subsp. fontanum (mapa 8)

Asplenium foreziense Le Grand ex Giraudias (mapa

9)

Asplenium hemionitis L. (mapa 9)

Asplenium hispanicum (Coss.) Greuter \& Burdet

(mapa 10)

Asplenium majoricum Litard. (mapa 10)

Asplenium marinum L. (mapa 11)

Asplenium obovatum Viv. subsp. obovatum (mapa 12)

Asplenium obovatum subsp. protobillotii Herrero,

Pajarón \& Prada (mapa 12)

Asplenium onopteris L. (mapa 13)

Asplenium petrarchae subsp. bivalens (D.E. Mey.)

Lovis \& Reichst. (mapa 14)

Asplenium petrarchae (Guérin) DC. subsp. petrarchae (mapa 15)

Asplenium ruta-muraria L. subsp. ruta-muraria (mapa 16)

Asplenium sagittatum (DC.) A. J. Bange (mapa 17)

Asplenium scolopendrium L. (mapa 18)

Asplenium selosii Leybold (mapa 17)

Asplenium septentrionale (L.) Hoffm. subsp. septentrionale (mapa 19)

Asplenium trichomanes subsp. hastatum (Christ) S.

Jess. (mapa 19)

Asplenium trichomanes subsp. inexpectans Lovis (mapa 19)

Asplenium trichomanes subsp. quadrivalens D.E.

Mey. (mapa 20)

Asplenium trichomanes L. subsp. trichomanes (mapa 21)
Asplenium viride Huds. (mapa 22)

Athyrium distentifolim Tausch ex Opiz (mapa 23)

Athyrium filix-femina (L.) Roth (mapa 24)

Azolla caroliniana Willd. (mapa 87)

Azolla filiculoides Lam. (mapa 87)

Blechnum spicant (L.) Roth subsp. spicant (mapa 25)

Botrychium lunaria (L.) Sw. (mapa 26)

Botrychium matricariifolium (Retz.) A. Braun ex

W. D. J. Koch (mapa 26)

Cheilanthes acrostica (Balbis) Tod. (mapa 27)

Cheilanthes guanchica C. Bolle (mapa 28)

Cheilanthes hispanica Mett. (mapa 29)

Cheilanthes maderensis Lowe (mapa 30)

Cheilanthes tinaei Tod. (mapa 31)

Christella dentata (Forssk.) Brownsey \& Jermy (mapa 31)

Cosentinia vellea (Aiton) Tod. (mapa 32)

Cryptogramma crispa (L.) R.Br. ex Hook. (mapa 32)

Culcita macrocarpa K. Presl (mapa 33)

Cystopteris dickieana R. Sim. (mapa 33)

Cystopteris fragilis (L.) Bernh. s.l. (mapa 34)

Cystopteris montana (Lam.) Bernh. ex Desv. (mapa 35)

Cystopteris viridula (Desv.) Desv. (mapa 35)

Davallia canariensis (L.) Sm. (mapa 36)

Diphasiastrum alpinum (L.) J. Holub (mapa 36)

Diplazium caudatum (Cav.) Jermy (mapa 37)

Dryopteris aemula (Ait.) Kuntze (mapa 37)

Dryopteris affinis (Lowe) Fraser-Jenk. subsp. affinis (mapa 38)

Dryopteris affinis subsp. borreri (Newman) FraserJenk. (mapa 39)

Dryopteris affinis subsp. cambrensis Fraser-Jenk. (mapa 40)

Dryopteris carthusiana (Vill.) H.P. Fuchs (mapa 41)

Dryopteris corleyi Fraser-Jenk. (mapa 41)

Dryopteris dilatata (Hoffm.) A. Gray (mapa 42)

Dryopteris expansa (C. Presl) Fraser-Jenk. \& Jermy (mapa 43)

Dryopteris filix-mas (L.) Schott (mapa 44)

Tabla 1. Relación de especies y mapas 
Dryopteris guanchica Gibby \& Jermy (mapa 45)

Dryopteris oreades Fomin (mapa 45)

Dryopteris pallida subsp. balearica (Litard.) Fraser-Jenk. (mapa 46)

Dryopteris remota (A. Braun) Hayek (mapa 46)

Dryopteris submontana (Fraser-Jenk. \& Jermy) Fraser-Jenk. (mapa 46)

Dryopteris tyrrhena Fraser-Jenk. \& Reichst. (mapa 47)

Equisetum arvense L. (mapa 48)

Equisetum fluviatile L. (mapa 49)

Equisetum hyemale L. (mapa 50)

Equisetum palustre L. (mapa 51)

Equisetum ramosissimum Desf. (mapa 52)

Equisetum sylvaticum L. (mapa 52)

Equisetum telmateia Ehrh. (mapa 53)

Equisetum variegatum Schleich. ex F. Weber \& D.

Mohr (mapa 54)

Gymnocarpium dryopteris (L.) Newman (mapa 55)

Gymnocarpium robertianum (Hoffm.) Newman (mapa 56)

Huperzia selago (L.) Bernh. ex Schrank \& Mart. subsp. selago (mapa 57)

Hymenophyllum tunbrigense (L.) Sm. (mapa 58)

Hymenophyllum wilsonii Hook. (mapa 58)

Isoetes creussensis Lazare \& S. Riba (mapa 58)

Isoetes durieui Bory (mapa 58)

Isoetes echinosporum Durieu (mapa 59)

Isoetes fluitans M. I. Romero (mapa 59)

Isoetes histrix Bory (mapa 60)

Isoetes lacustris L. (mapa 60)

Isoetes setaceum Lam. (mapa 61)

Isoetes velatum subsp. asturicense (Laínz) Rivas

Mart. \& Prada (mapa 62)

Isoetes velatum $\mathrm{A}$. Braun subsp. velatum (mapa 62)

Lycopodiella cernua (L.) Pic. Serm. (mapa 87)

Lycopodiella inundata (L.) Holub (mapa 63)

Lycopodium annotinum L. (mapa 63)

Lycopodium clavatum L. (mapa 64)

Marsilea batardae Launert (mapa 65)

Marsilea quadrifolia L. (mapa 65)
Marsilea strigosa Willd. (mapa 65)

Notholaena marantae (L.) R. Br. subsp. marantae (mapa 66)

Ophioglossum azoricum K. Presl (mapa 67)

Ophioglossum lusitanicum L. (mapa 68)

Ophioglossum vulgatum L. (mapa 69)

Oreopteris limbosperma (All.) Holub (mapa 70)

Osmunda regalis L. (mapa 71)

Pellaea calomelanos (Sw.) Link (mapa 72)

Phegopteris connectilis (Michx.) Watt (mapa 72)

Pilularia globulifera L. (mapa 72)

Pilularia minuta Durieu (mapa 73)

Polypodium cambricum L. subsp. cambricum (mapa 74)

Polypodium interjectum Shivas (mapa 75)

Polypodium vulgare L. (mapa 76)

Polystichum aculeatum (L.) Roth (mapa 77)

Polystichum lonchitis (L.) Roth (mapa 78)

Polystichum setiferum (Forssk.) Moore ex Woynar (mapa 79)

Psilotum nudum (L.) P. Beauv. (mapa 78)

Pteridium aquilinum (L.) Kuhn subsp. aquilinum (mapa 80)

Pteris cretica L. (mapa 88)

Pteris incompleta Cav. (mapa 81)

Pteris vittata L. (mapa 81)

Salvinia natans (L.) All. (mapa 88)

Selaginella denticulata (L.) Spring (mapa 82)

Selaginella kraussiana (Kuntze) A. Braun (mapa 88)

Selaginella selaginoides (L.) P. Beauv. ex Mart. \& Schrank (mapa 82)

Stegnogramma pozoi (Lag.) K. Iwats. (mapa 83)

Thelypteris palustris Schott (mapa 84)

Vandenboschia speciosa (Willd.) G. Kunkel (mapa 85)

Woodsia alpina (Bolton) Gray (mapa 85)

Woodsia glabella subsp. pulchella (Bertol.) Á.

Löve \& D. Löve (mapa 85)

Woodwardia radicans (L.) Sm. (mapa 86)

Tabla 1 (continuación). Relación de especies y mapas correspondientes: 


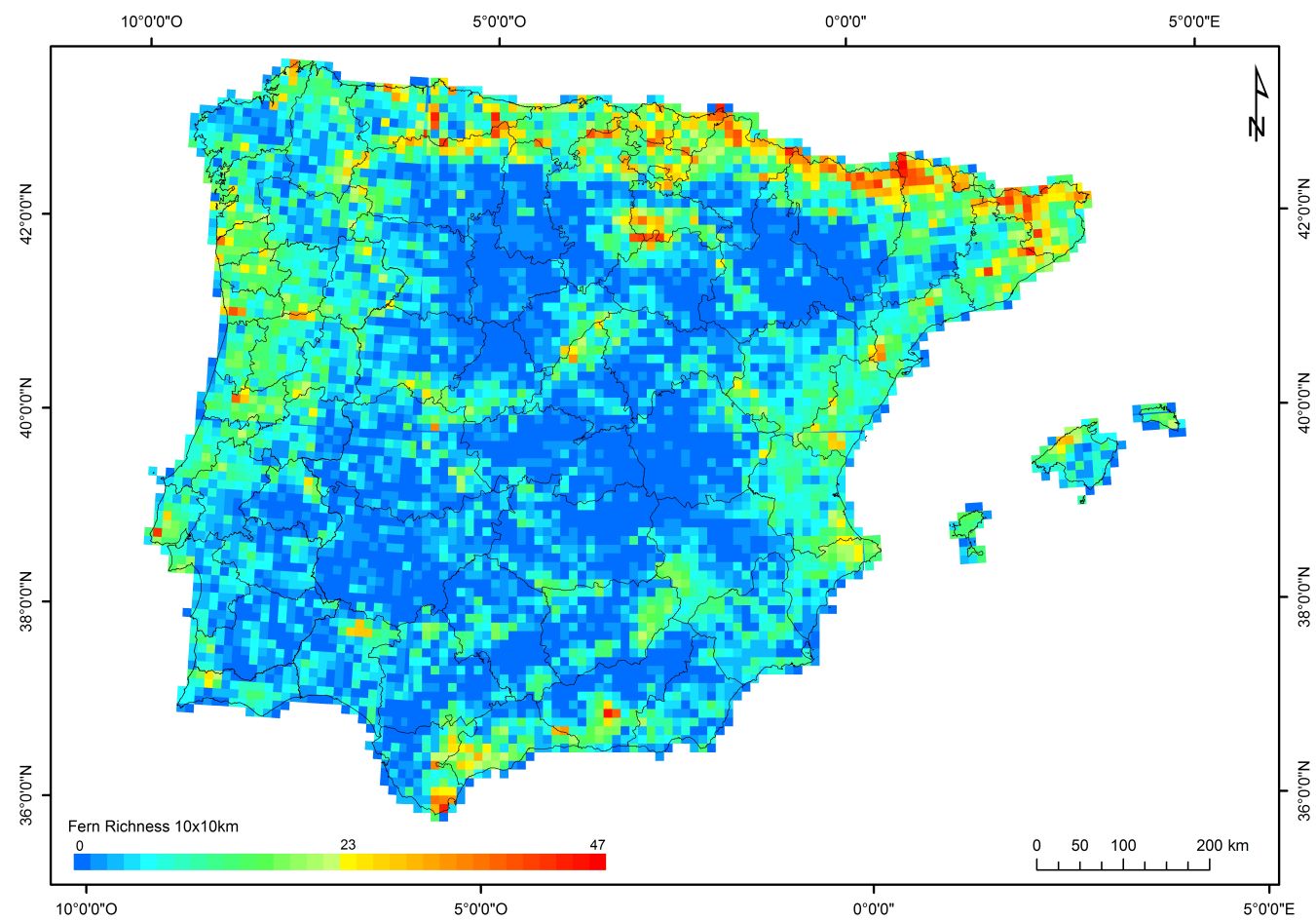

Figura 1: Mapa de la riqueza de pteridófitos en la Península Ibérica e Islas Baleares. Se han dibujado las provincias españolas, los distritos portugueses y el contorno de Andorra. Cada cuadrado del mapa representa una cuadrícula UTM de 10 x $10 \mathrm{~km}$. Map of Iberian and Balearic pteridophyte richness. The contour of Spanish provinces, Portuguese districts and Andorra have been drawn. Each square represents a UTM cell of $10 \times 10 \mathrm{~km}$.

\section{BIBLIOGRAFÍA}

AMARAL FRANCO, J.M.A. \& M.L. ROCHA AFONSO -1983- Distribuição de pteridófitos e gimnospérmicas em Portugal. 2a Edición. Serviço Nacional de Parques, Reservas e Património Paisagistico, Lisboa.

BARRINGTON, D.S. -1993- Ecological and historical factors in fern biogeography. $J$. Biogeogr. 20: 275-280.

BELMONTE ANDÚJAR, R., S. PAJARÓN SOTOMAYOR \& E. PANGUA FERNÁNDEZVALDÉS -2011- Helechos de la provincia de Albacete. Sabuco 8: 9-68.

BIRKS, H.J.B. -1976- The distribution of European pteridophytes: a numerical analysis. New Phytol. 77: 257-287.
BOLÒS, O. -1998- Atlas corològic de la flora vascular dels Països Catalans. Primera compilació general. 2 Vols. Institut d'Estudis Catalans, Barcelona.

BYSTRIAKOVA, N., S.W. ANSELL, S.J. RUSSELL, M. GRUNDMANN, J.C. VOGEL \& H. SCHNEIDER -2014- Present, past and future of the European rock fern Asplenium fontanum: combining distribution modelling and population genetics to study the effect of climate change on geographic range and genetic diversity. Annals Bot. 113: 453-465.

CABEZUDO, B. \& M.M. TRIGO -2004- Pteridófitos (Helechos y plantas afines) in: BLANCA, G. \& A. ORTEGA (COORDS.) Proyecto Andalucia: La Naturaleza en Andalucía. Vol. XXI. Págs. 315-374. Grupo Hercules. Sevilla 
CARRIÓN VILCHES, M.A., P. SÁNCHEZ GÓMEZ, J. GUERRA MONTES, A. HERNÁNDEZ GONZÁLEZ, A.F. CARRILLO LÓPEZ, J.F. JIMÉNEZ MARTÍNEZ, J. GARCÍA RODRÍGUEZ \& J.F. MARTÍNEZ FERNÁNDEZ -2000- Helechos de la Región de Murcia. Universidad de Murcia-Caja de Ahorros del Mediterráneo, Murcia.

CASTROVIEJo, S., M. LAÍNZ, G. LÓPEZ GONZÁLEZ, P. MONTSERRAT, F. MUÑOZ GARMENDIA, J. PAIVA \& L. VILLAR, eds. -1986- Flora iberica. Vol. I: LycopodiaceaePapaveraceae. Real Jardín Botánico, Madrid.

CHIARUCCI, A., G. BACARO, K. A. TRIANTIS \& J.M. FERNÁNDEZ-PALACIOS -2011Biogeographical determinants of pteridophytes and spermatophytes on oceanic archipelagos. Syst. Biodivers. 9: 191-201.

FERRER-CASTÁN, D. \& O.R. VETAAS -2005Pteridophyte richness, climate and topography in the Iberian Peninsula: comparing spatial and nonspatial models of richness patterns. Global Ecol. Biogeogr. 14: 155-165.

JALAS, J. \& J. SUOMINEN, eds. -1972-Atlas Florae Europaeae. Vol 1. Pteridophyta (Psilotaceae to Azollaceae). The Committee for Mapping the Flora of Europe and Societas Biologica Fennica Vanamo, Helsinki.

MÁRQUEZ, A.L, R. REAL, J.M. VARGAS \& A.E. SALVO -1997- On identifying common distribution patterns and their causal factors: a probabilistic method applied to pteridophytes in the Iberian Peninsula. J. Biogeogr. 24: 613-631.

MORENO SAIZ, J.C., I. CASTRO PARGA, C.J. HUMPHRIES \& P.H. WILLIAMS -1996Strengthening the National and Natural Park system of Iberia to conserve pteridophytes in: CAMUS, J.M., M. GIBBY \& R.J. JOHNS (EDS.) Pteridology in Perspective. Págs. 101-123. Royal Botanic Gardens, Kew.

MORENO SAIZ, J.C. \& J.M. LOBO -2008- Iberian pteridophyte regions and their explanatory variables. Plant Ecol. 198: 149-167.

MUÑOZ, J., A.M. FELICÍSIMO, F. CABEZAS, A.R. BURGAZ \& I.MARTÍNEZ -2004- Wind as a long-distance dispersal vehicle in the Southern Hemisphere. Science 304: 1144-1147.

NAGALINGUM N.S., N. KNERR, S.W. LAFFAN, C.E. GONZÁLEZ-OROZCO, A.H. THORNHILL, J.T. MILLER \& B.D. MISHLER
-2015-Continental scale patterns and predictors of fern richness and phylogenetic diversity. Front. Genet. 6: 132.

PAUSAS, J.G. \& L. SÁEZ -2000- Pteridophyte richness in the NE Iberian Peninsula: biogeographic patterns. Plant Ecol. 148: 195-205.

PICHI SERMOLLI, R.E.G., L. ESPAÑA \& A.E. SALVO -1988- El valor biogeográfico de la pteridoflora ibérica. Lazaroa 10: 187-205.

PRYER, K.M., H. SCHNEIDER, A.R. SMITH, R. CRANFILL, P.G. WOLF, J.S. HUNT \& S.D. SIPES -2001- Horsetails and ferns are a monophyletic group and the closest living relatives to seed plants. Nature 409: 618-622.

PRYER, K.M., E. SCHUETTPELZ, P.G. WOLF, H. SCHNEIDER, A.R. SMITH \& R. CRANFILL -2004- Phylogeny and evolution of ferns (Monilophytes) with a focus on the early leptosporangiate divergences. Amer. J. Bot. 91: 1582-1598.

RICHARD, M., T. BERNARD \& G. BELL -2000Environmental heterogeneity and the spatial structure of fern species diversity in one hectare of old-growth forest. Ecography 23: 231-245.

SÁEZ, L. -1997- Atlas pteridològic de Catalunya i Andorra. Acta Bot. Barcinon. 44: 39-167.

SALVO, A.E., B. CABEZUDO \& L. ESPAÑA -1984- Atlas de la pteridoflora ibérica y balear. Acta Bot. Malacitana 9: 105-128.

SEGURA ZUBIZARRETA, A., G. MATEO SANZ \& J.L. BENITO ALONSO -2000- Catálogo florístico de la provincia de Soria. $2^{\mathrm{a}}$ Edición. Diputación Provincial de Soria, Soria.

SMITH, A.R. -1972- Comparison of fern and flowering plant distribution with some evolutionary interpretation for ferns. Biotropica 4: 4-9.

SMITH, A.R. -1993- Phytogeographic principles and their use in understanding fern relationships. $J$. Biogeogr. 20: 255-264.

VILLAR, L., J.A. SESÉ \& J.V. FERRÁNDEZ -1997- Atlas de la flora del Pirineo Aragonés, Vol. 1. Consejo de Protección de la Naturaleza de Aragón-Instituto de Estudios Altoaragoneses, Huesca.

VOGEL, J.C., F.J. RUMSEY, J.J. SCHNELLER, J.A. BARRET \& M.GIBBY -1999- Where are the glacial refugia in Europe? Evidence from pteridophytes. Biol. J. Linn. Soc. 66: 23-37. 

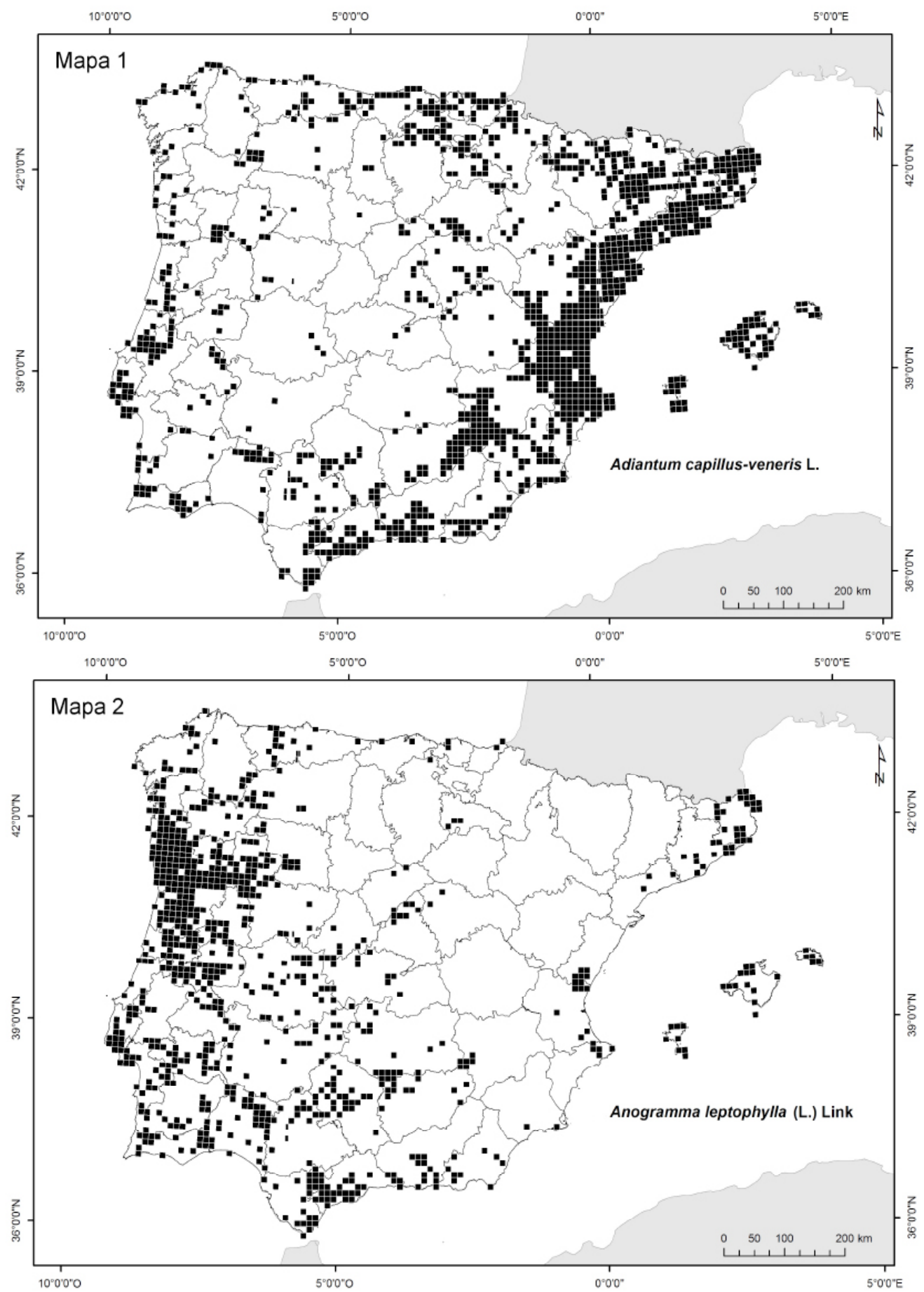

Figura 2. Atlas pteridológico. Mapas 1 y 2. 

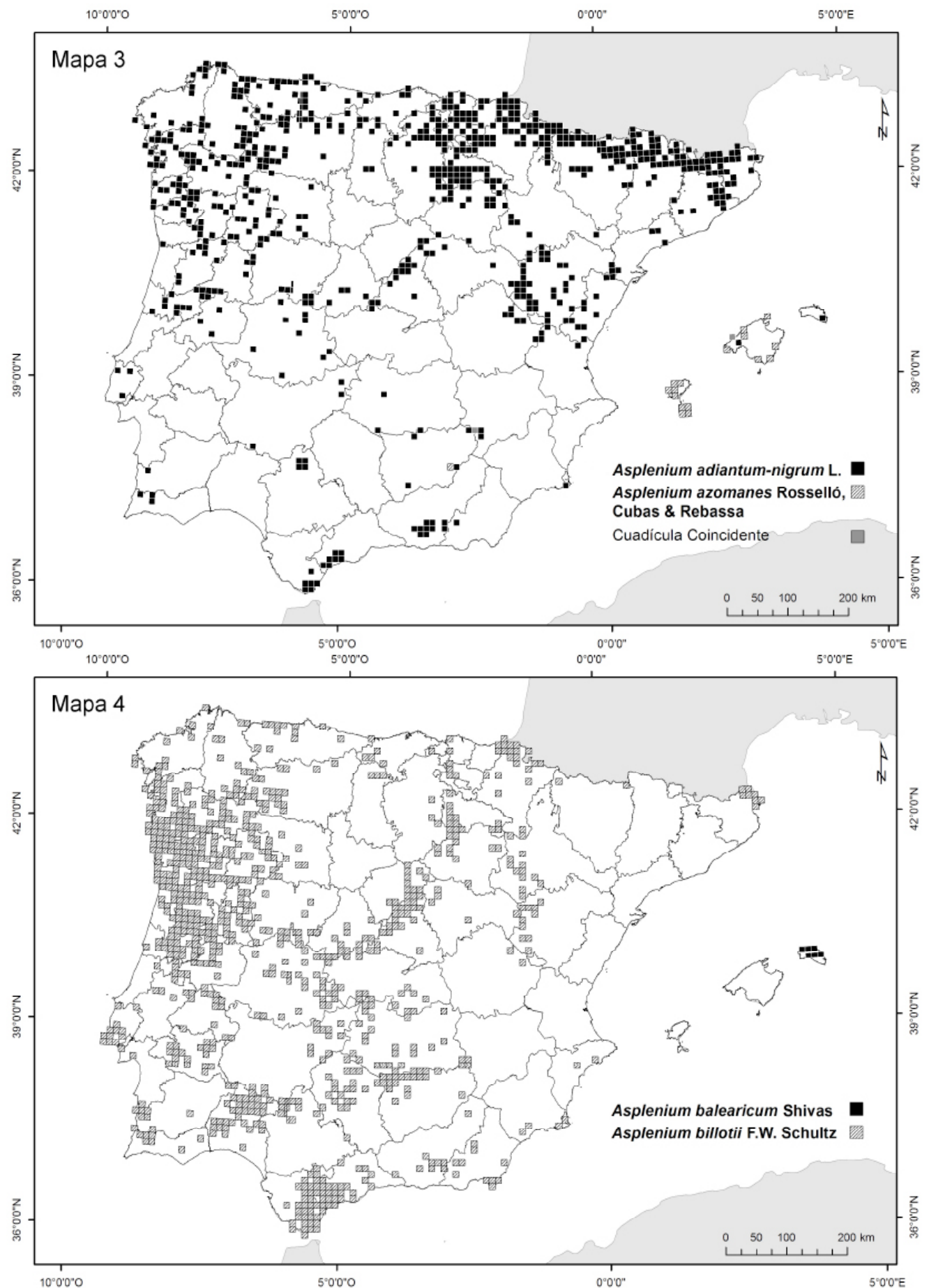

Figura 2. Atlas pteridológico. Mapas 3 y 4. 

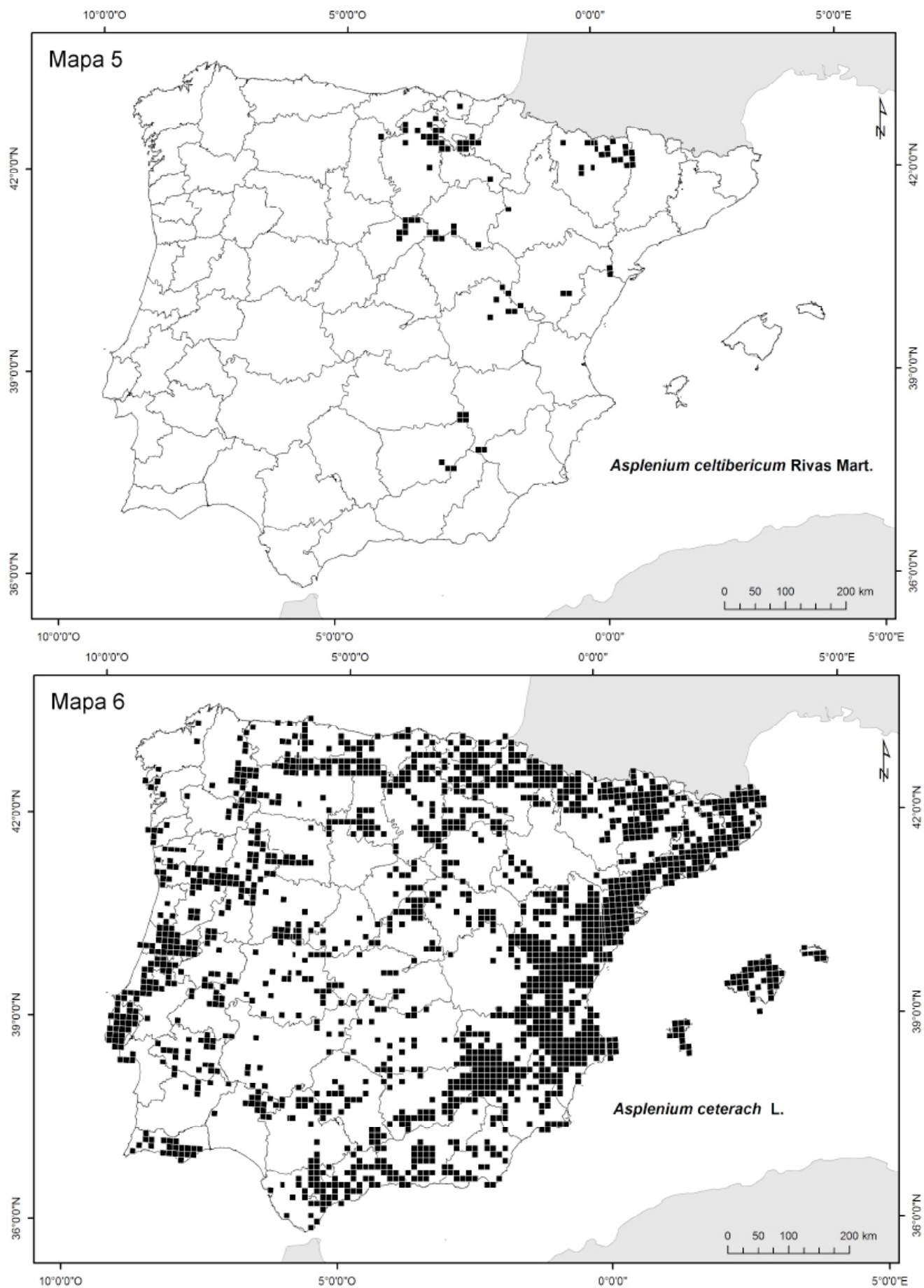

Figura 2. Atlas pteridológico. Mapas 5 y 6 . 

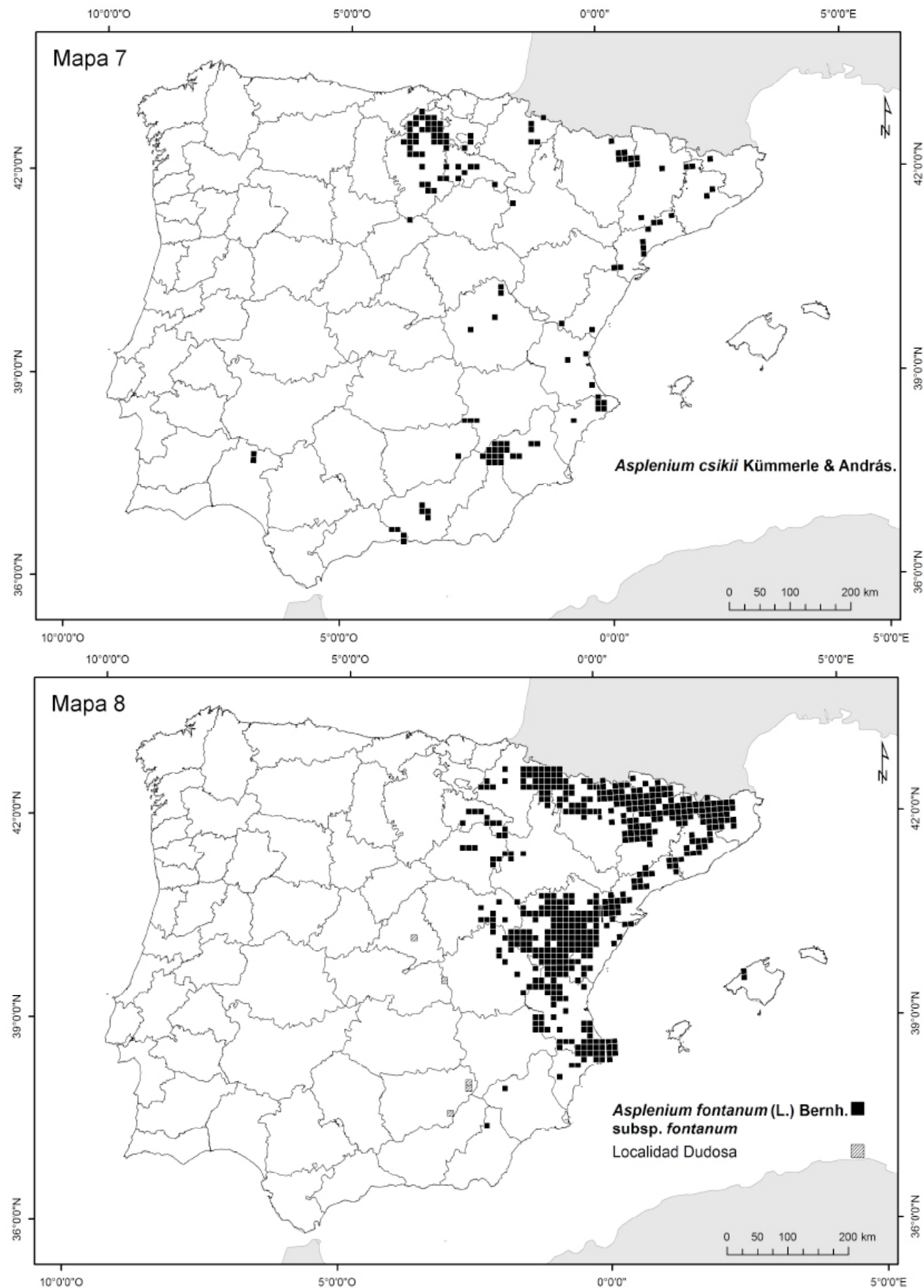

Figura 2. Atlas pteridológico. Mapas 7 y 8 . 

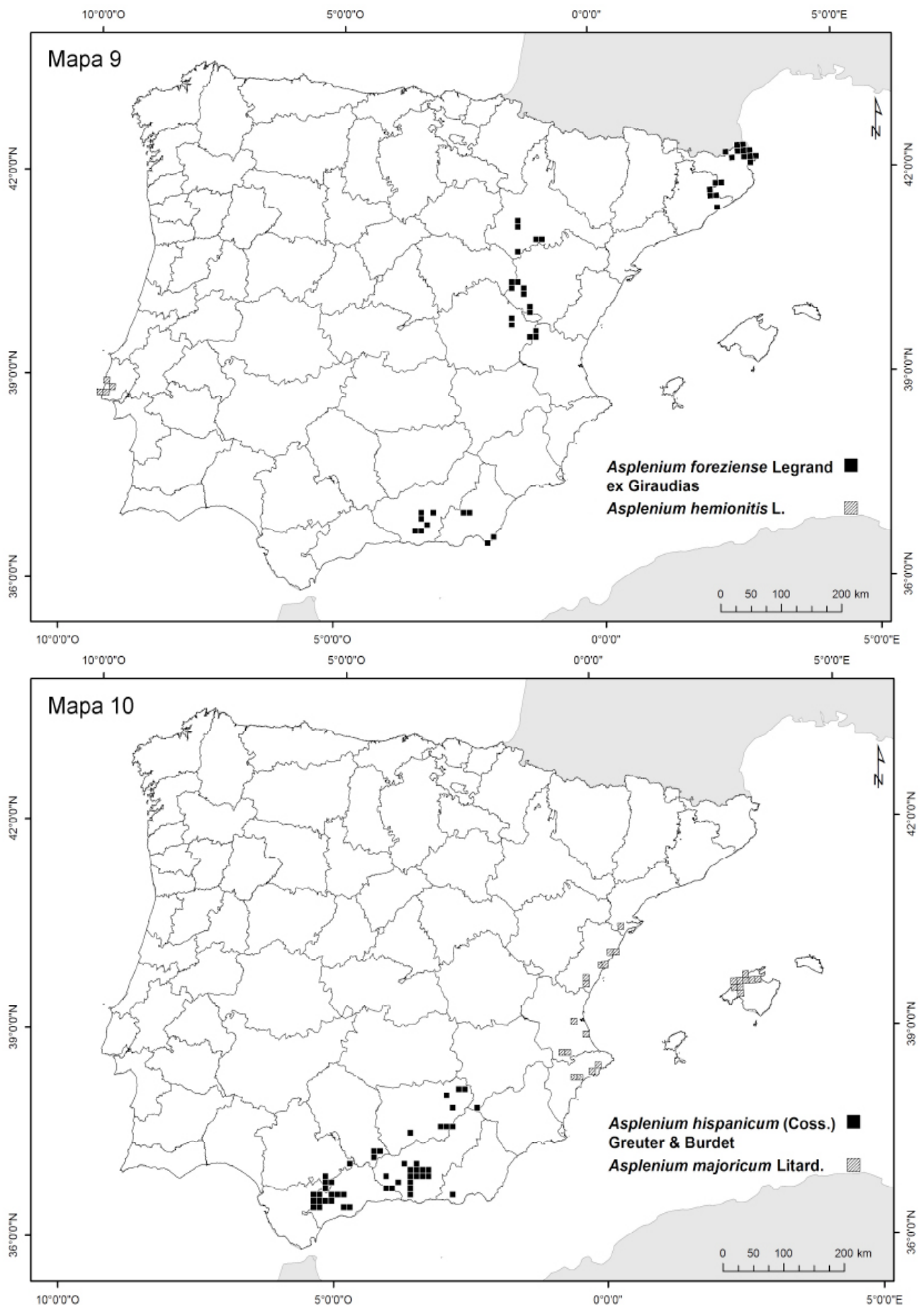

Figura 2. Atlas pteridológico. Mapas 9 y 10. 

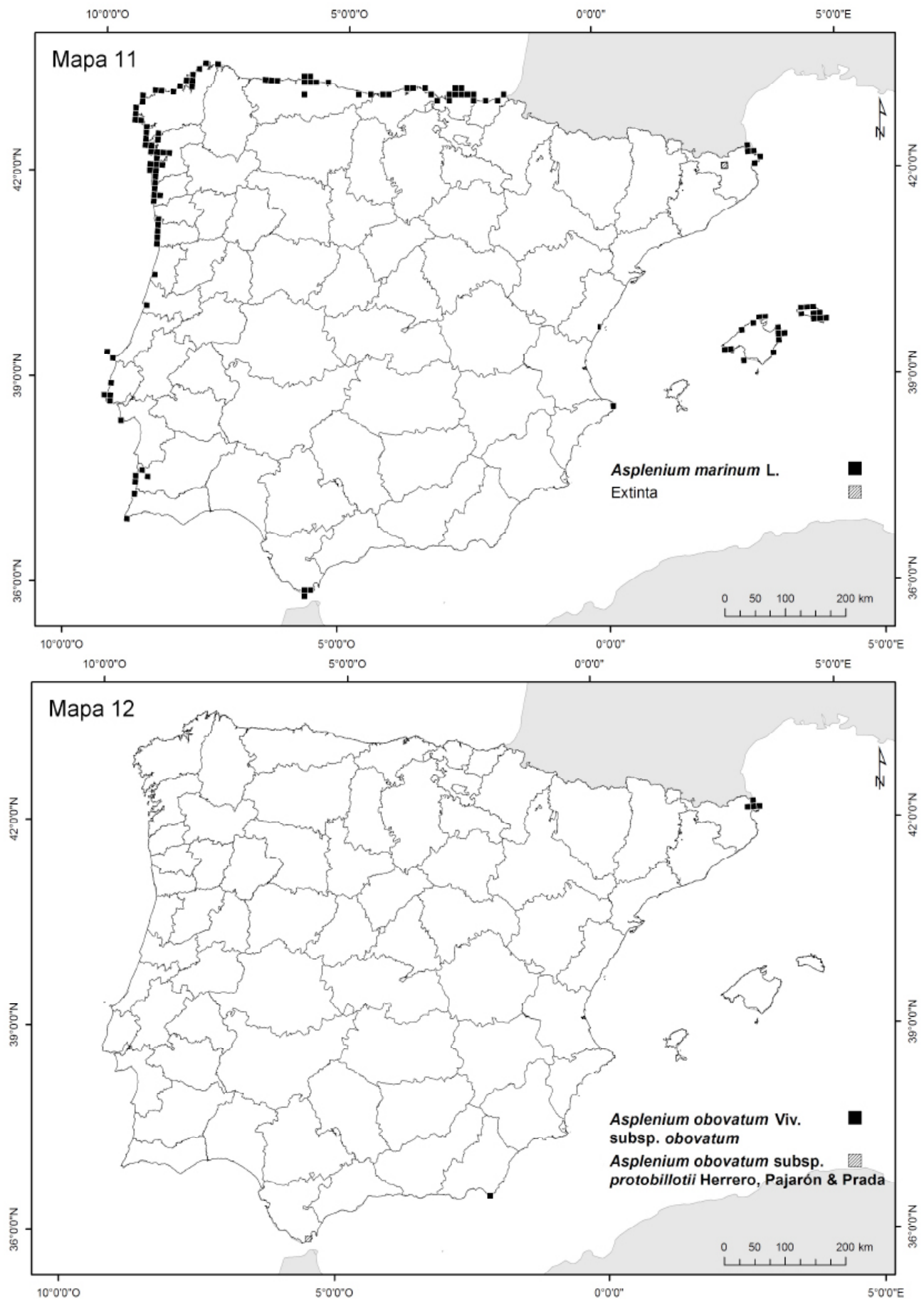

Figura 2. Atlas pteridológico. Mapas 11 y 12. 

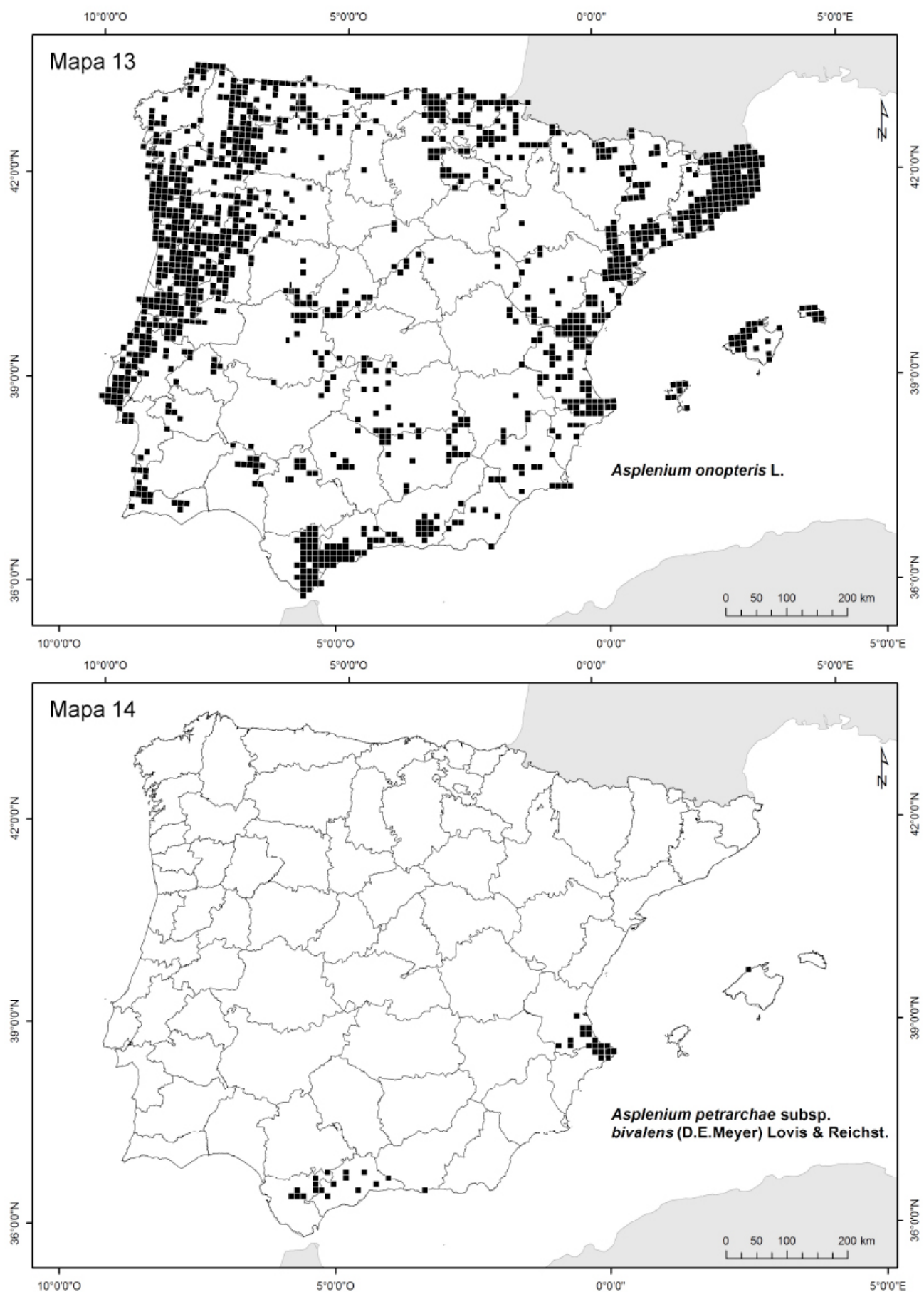

Figura 2. Atlas pteridológico. Mapas 13 y 14. 

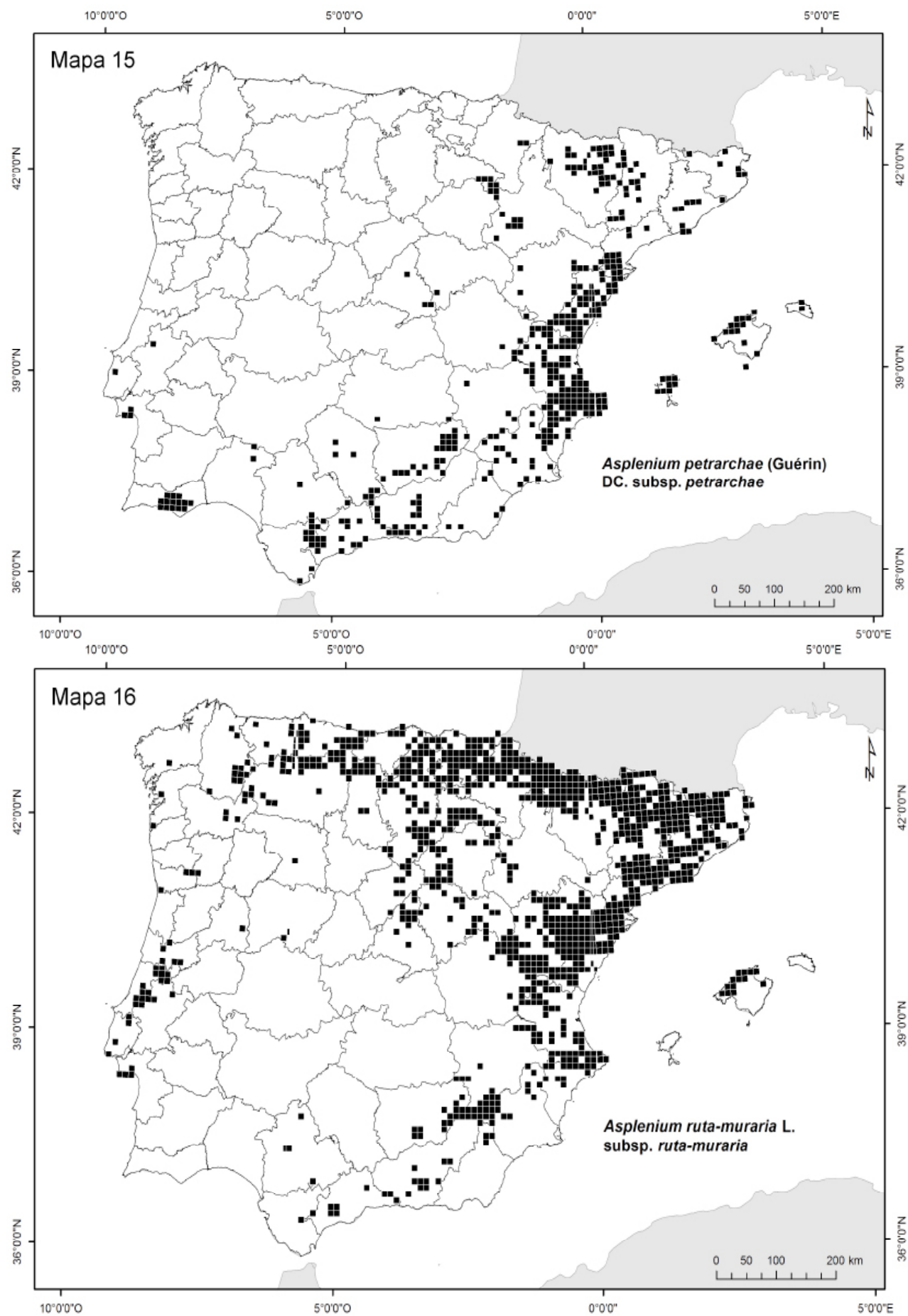

Figura 2. Atlas pteridológico. Mapas 15 y 16. 

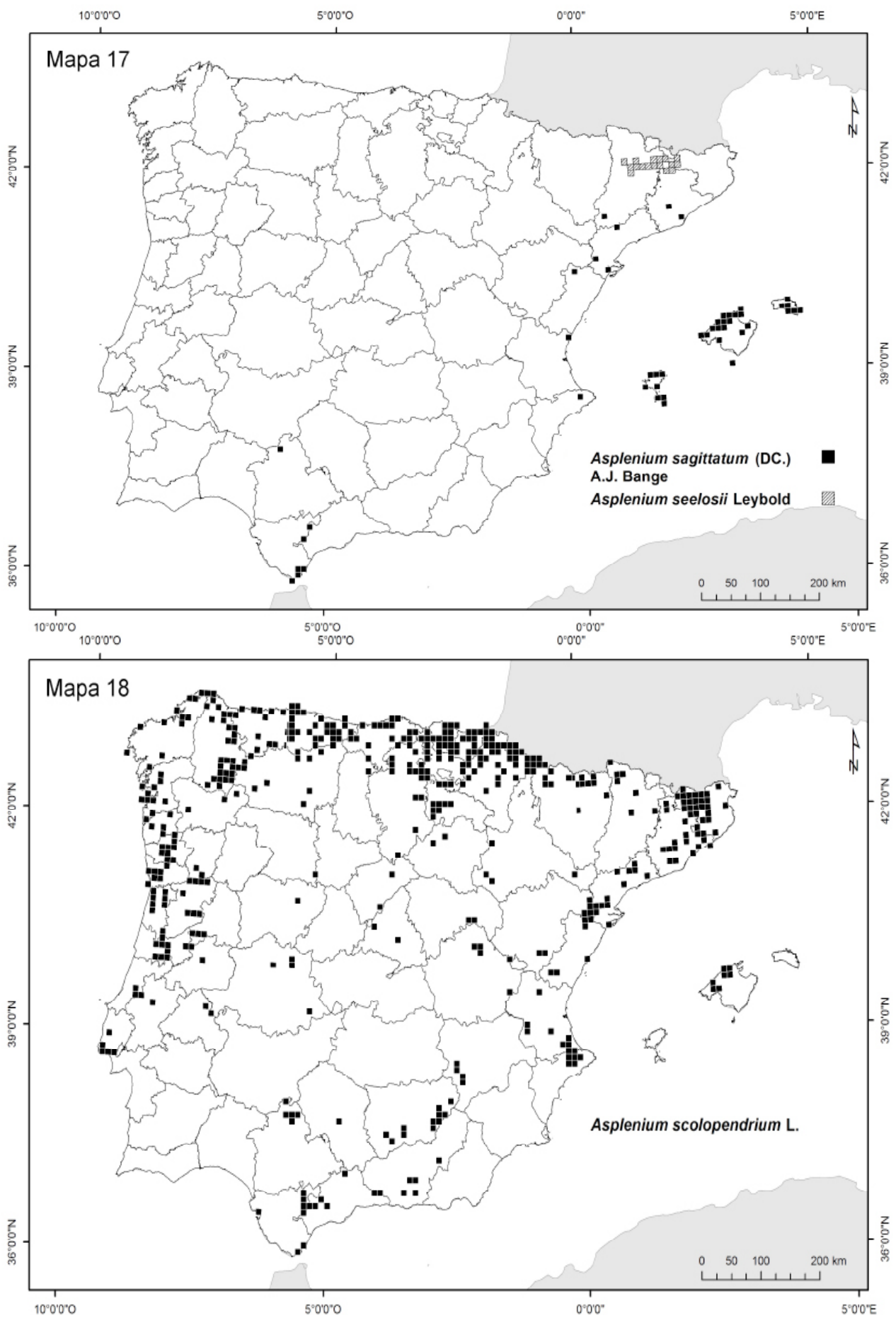

Figura 2. Atlas pteridológico. Mapas 17 y 18. 

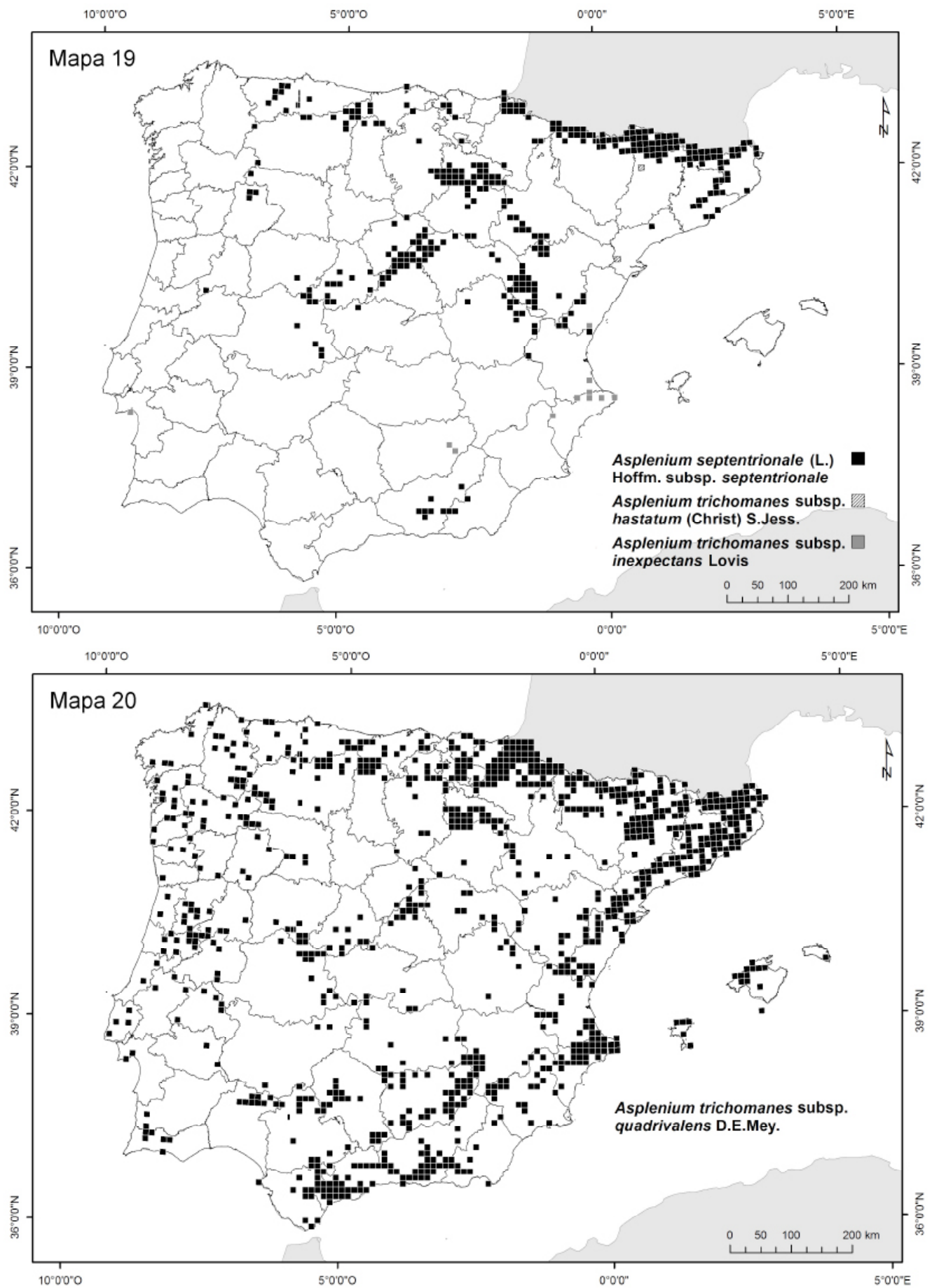

Figura 2. Atlas pteridológico. Mapas 19 y 20. 

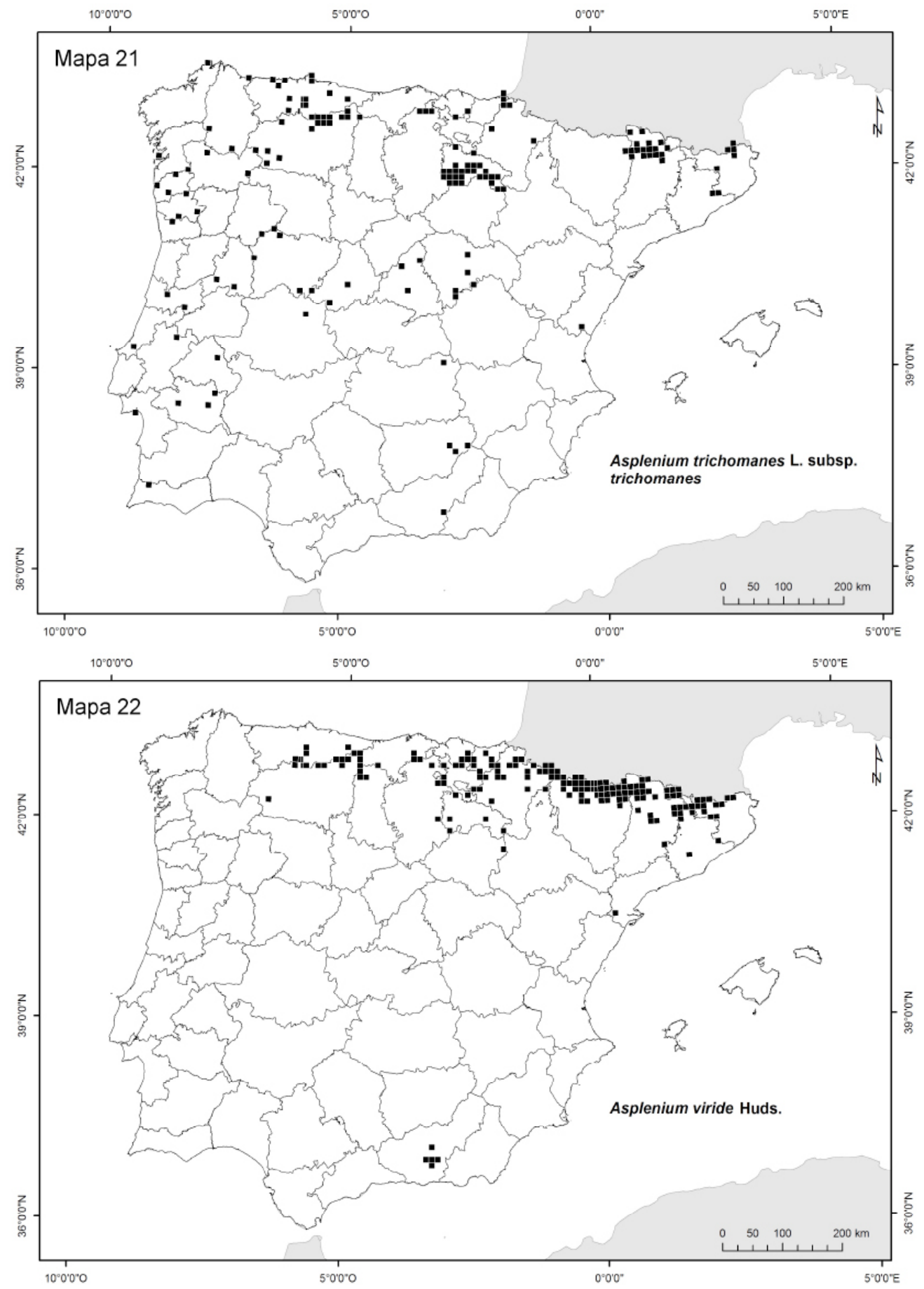

Figura 2. Atlas pteridológico. Mapas 21 y 22. 

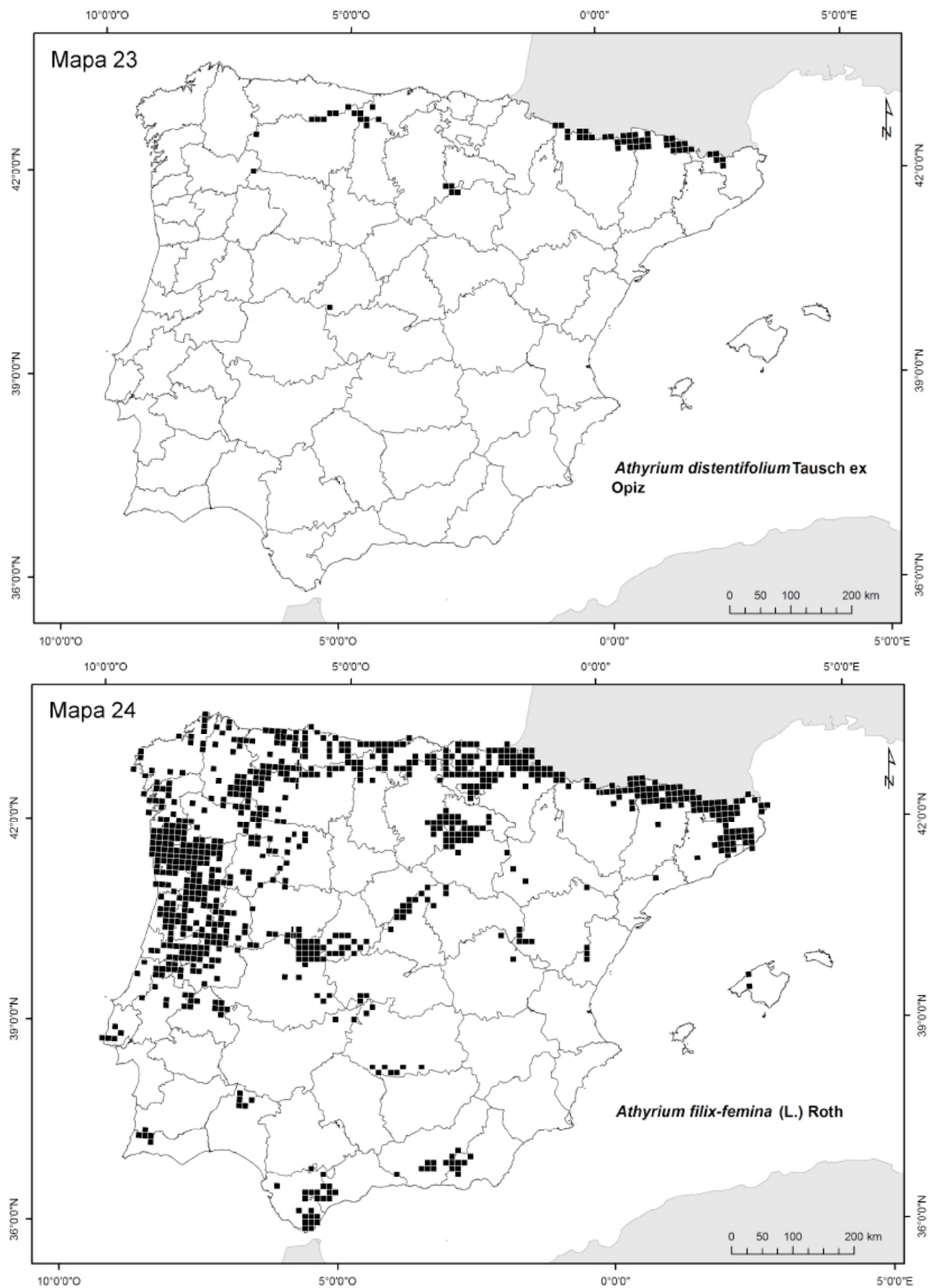

Figura 2. Atlas pteridológico. Mapas 23 y 24. 

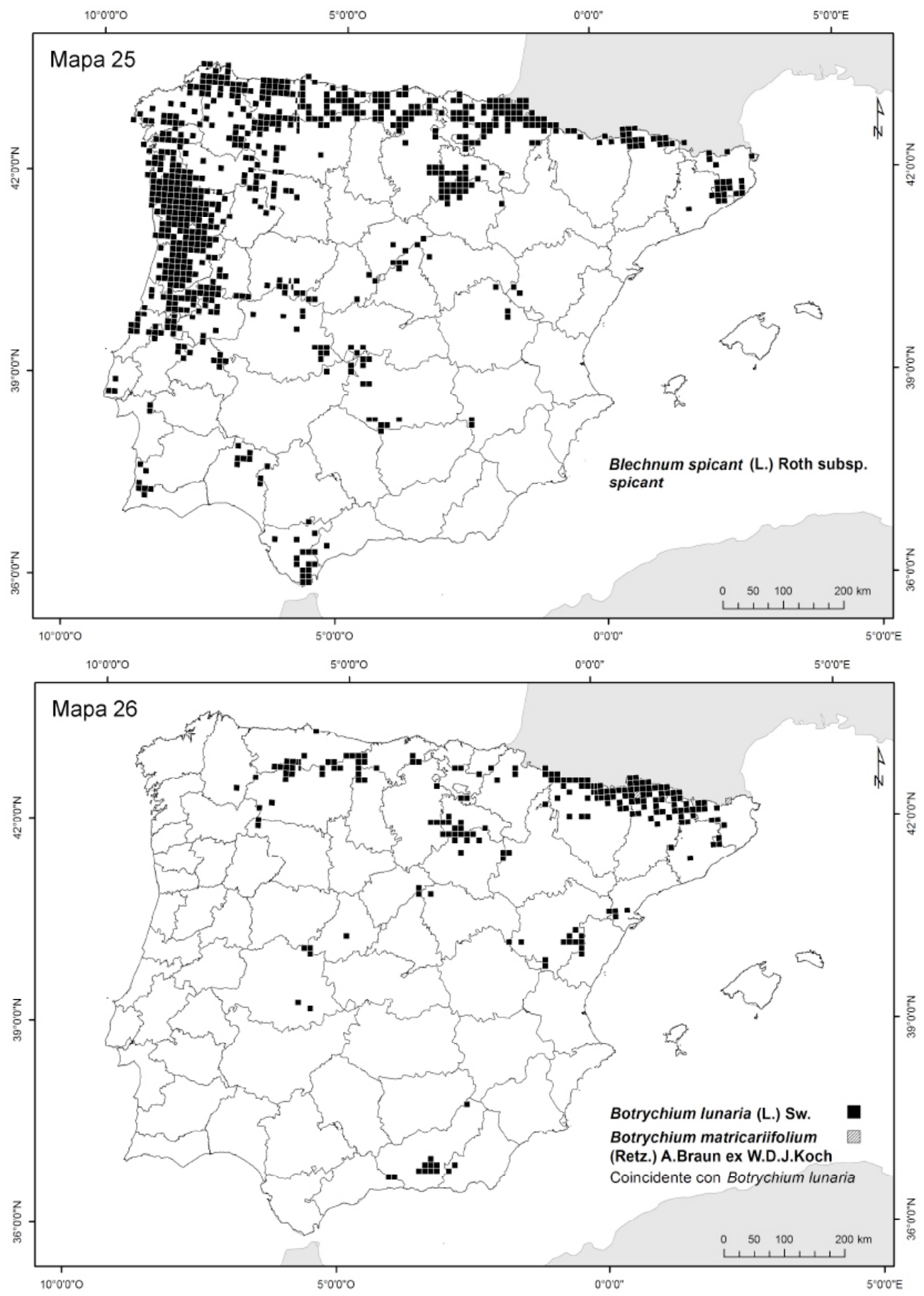

Figura 2. Atlas pteridológico. Mapas 25 y 26. 

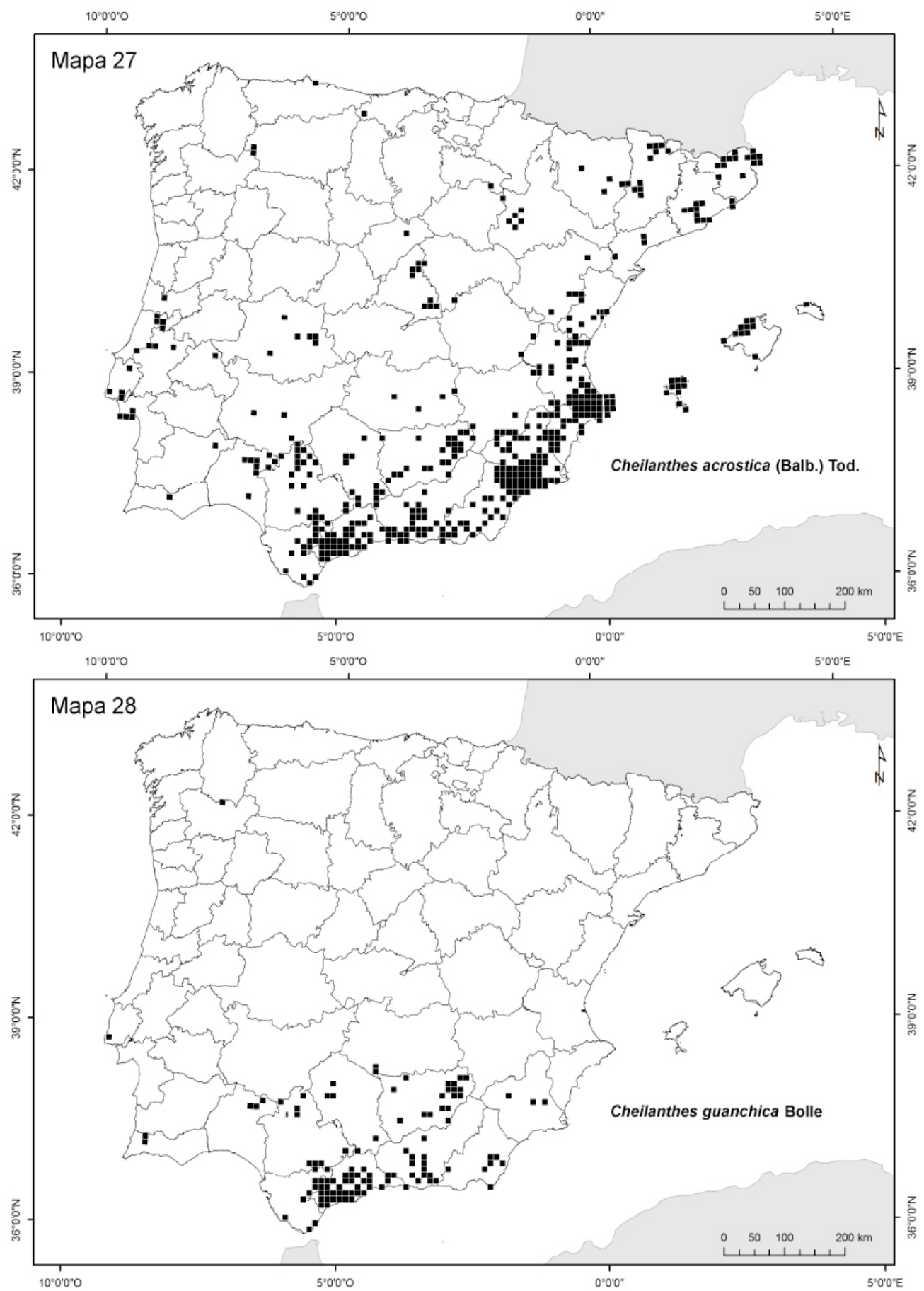

Figura 2. Atlas pteridológico. Mapas 27 y 28. 

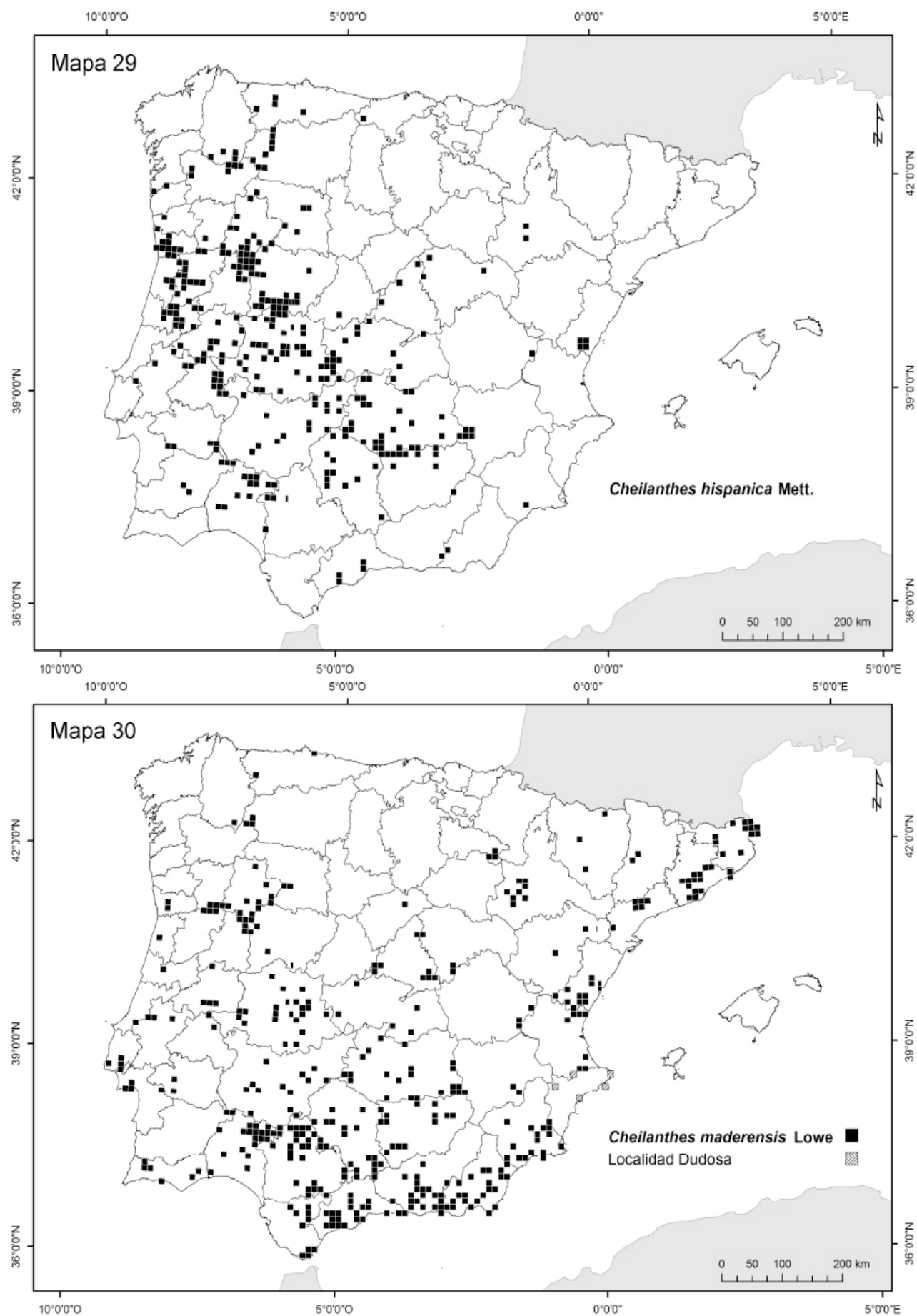

Figura 2. Atlas pteridológico. Mapas 29 y 30. 

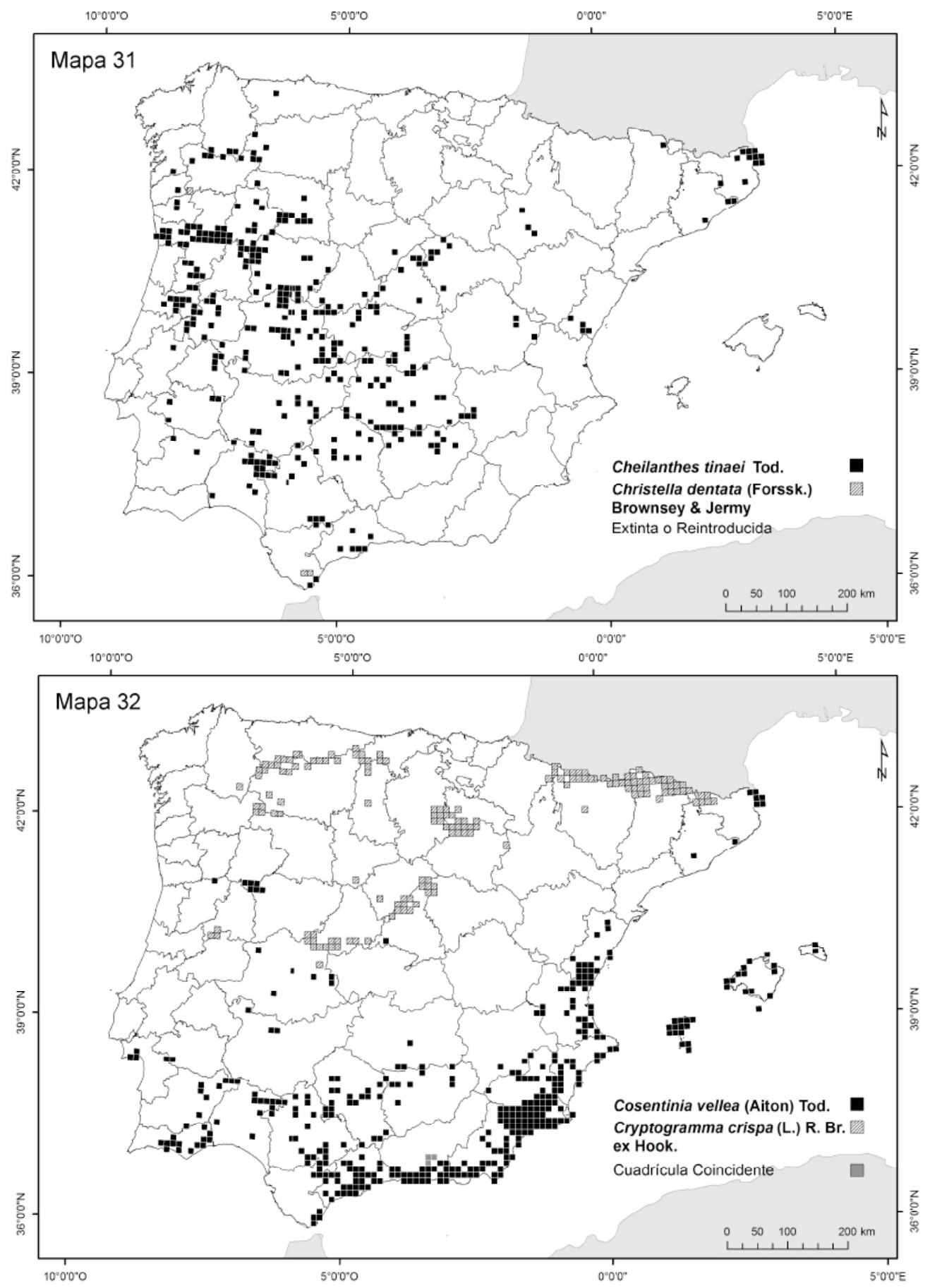

Figura 2. Atlas pteridológico. Mapas 31 y 32. 

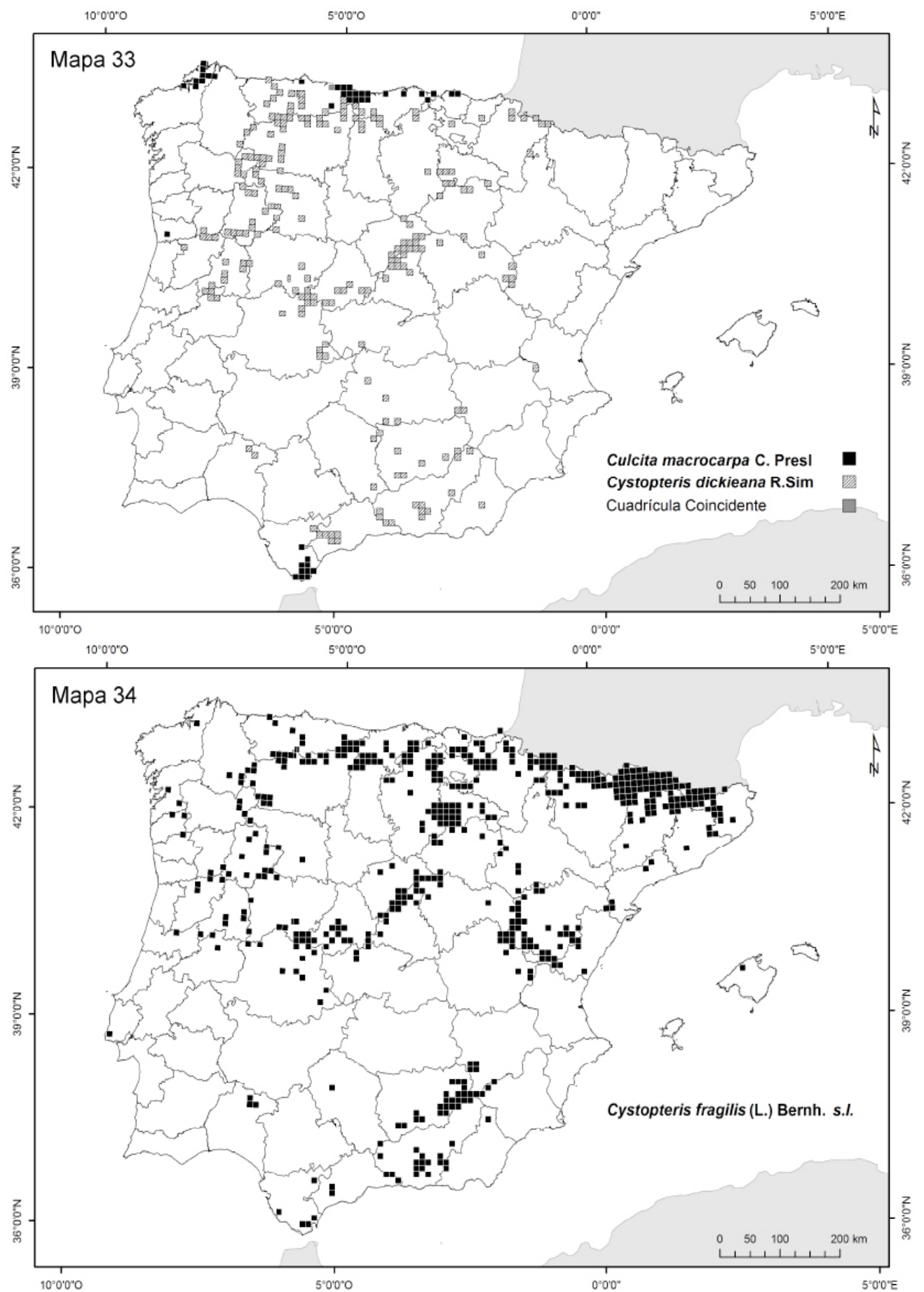

Figura 2. Atlas pteridológico. Mapas 33 y 34 . 

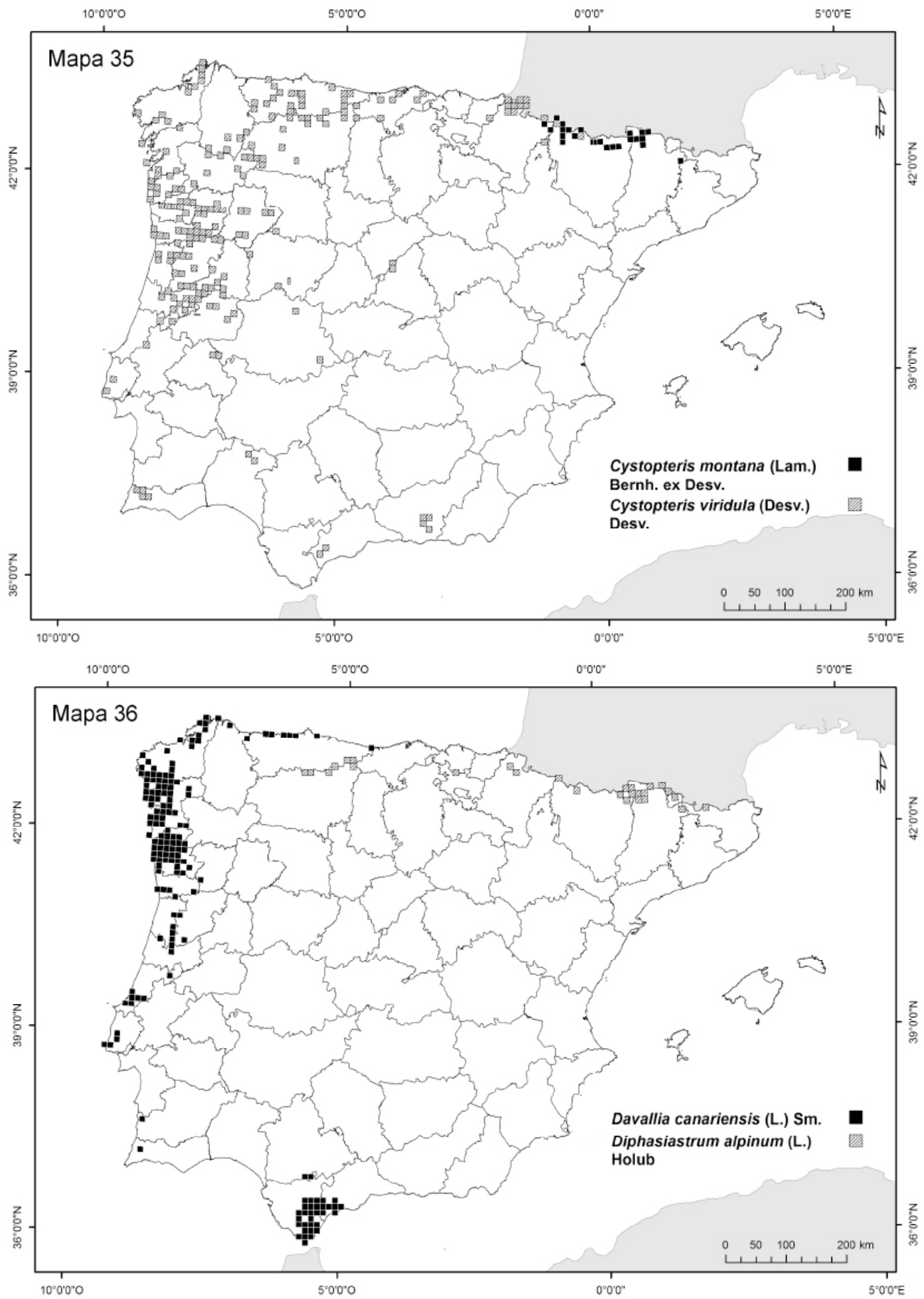

Figura 2. Atlas pteridológico. Mapas 35 y 36. 

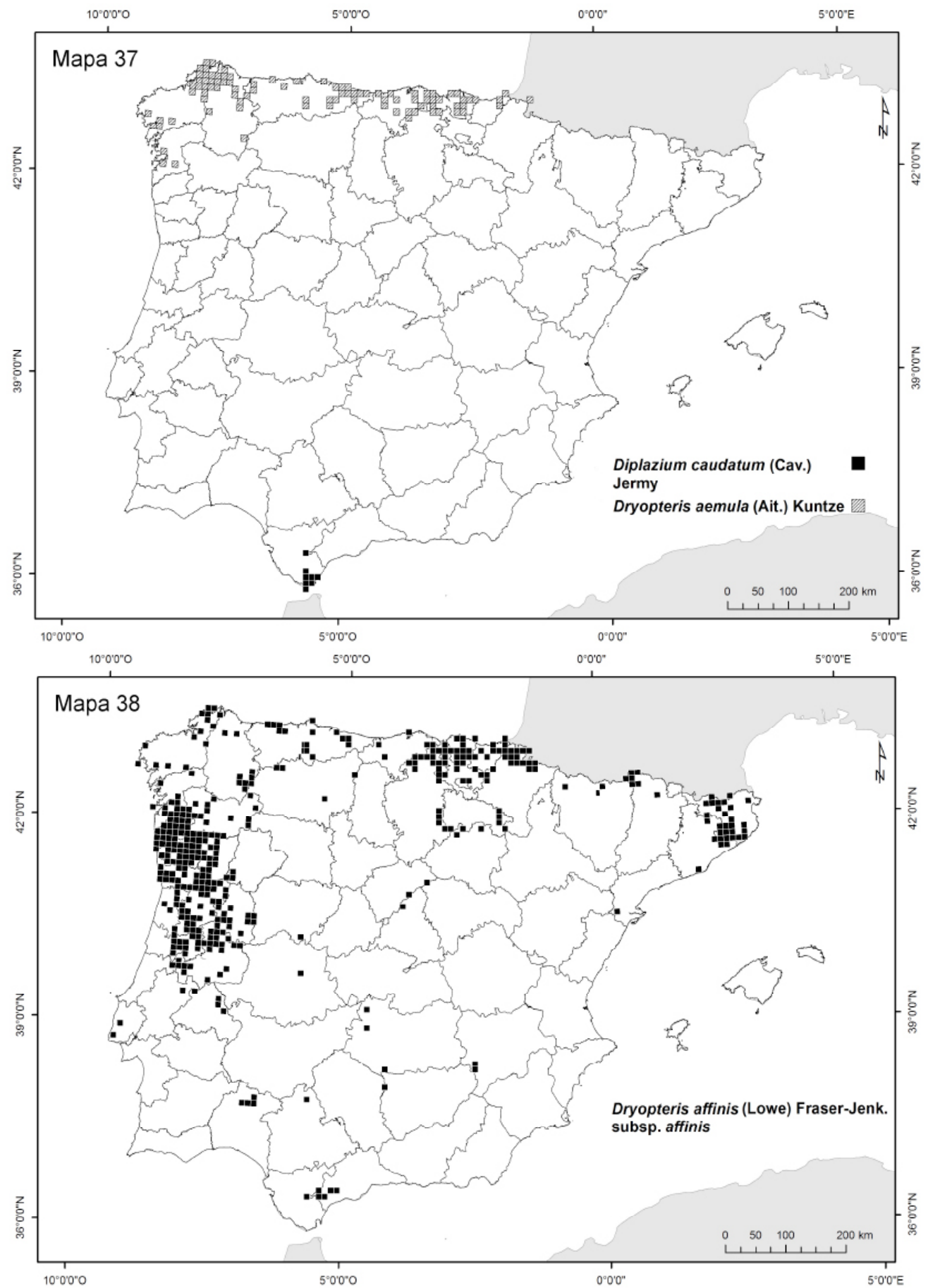

Figura 2. Atlas pteridológico. Mapas 37 y 38 . 

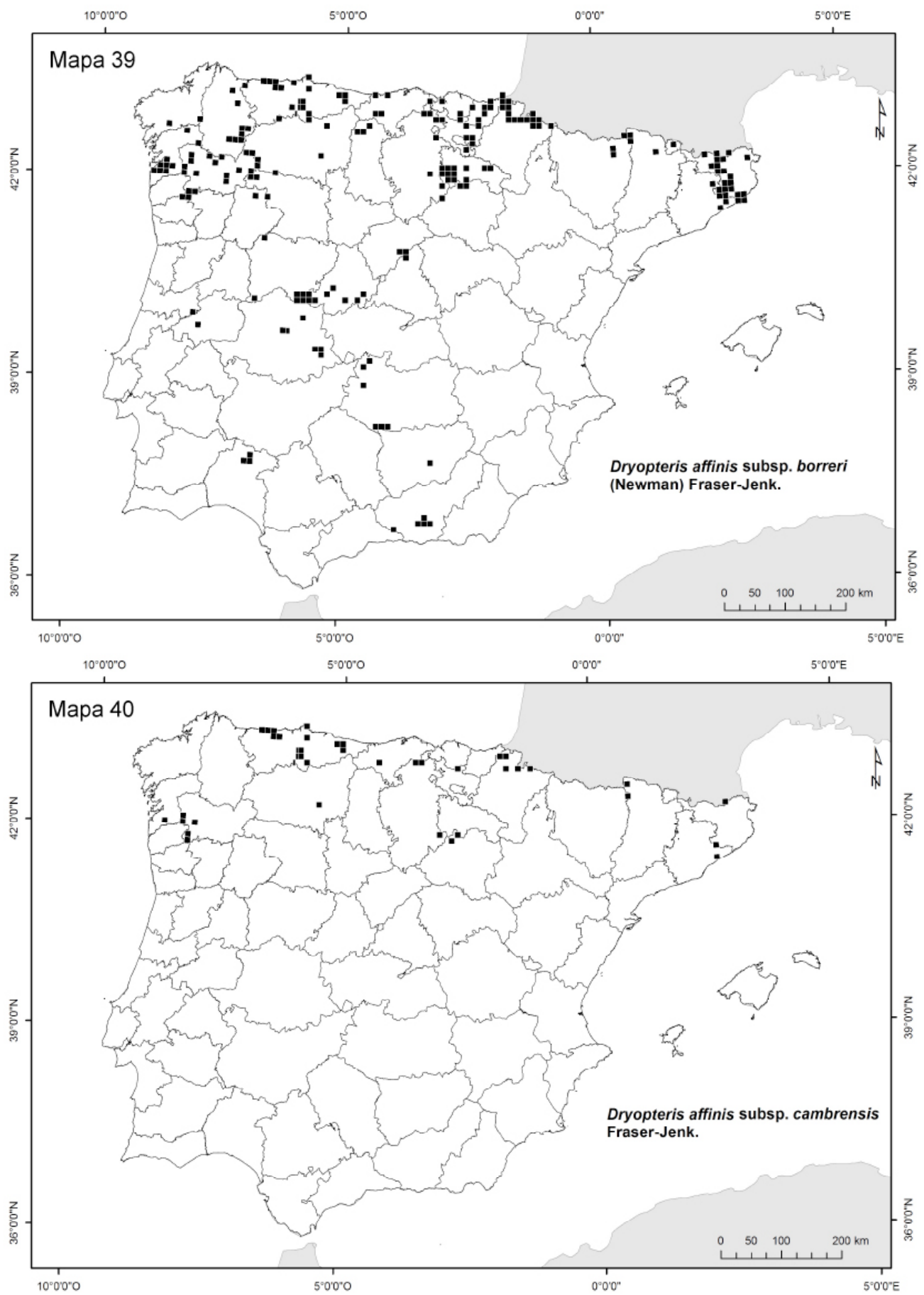

Figura 2. Atlas pteridológico. Mapas 39 y 40. 

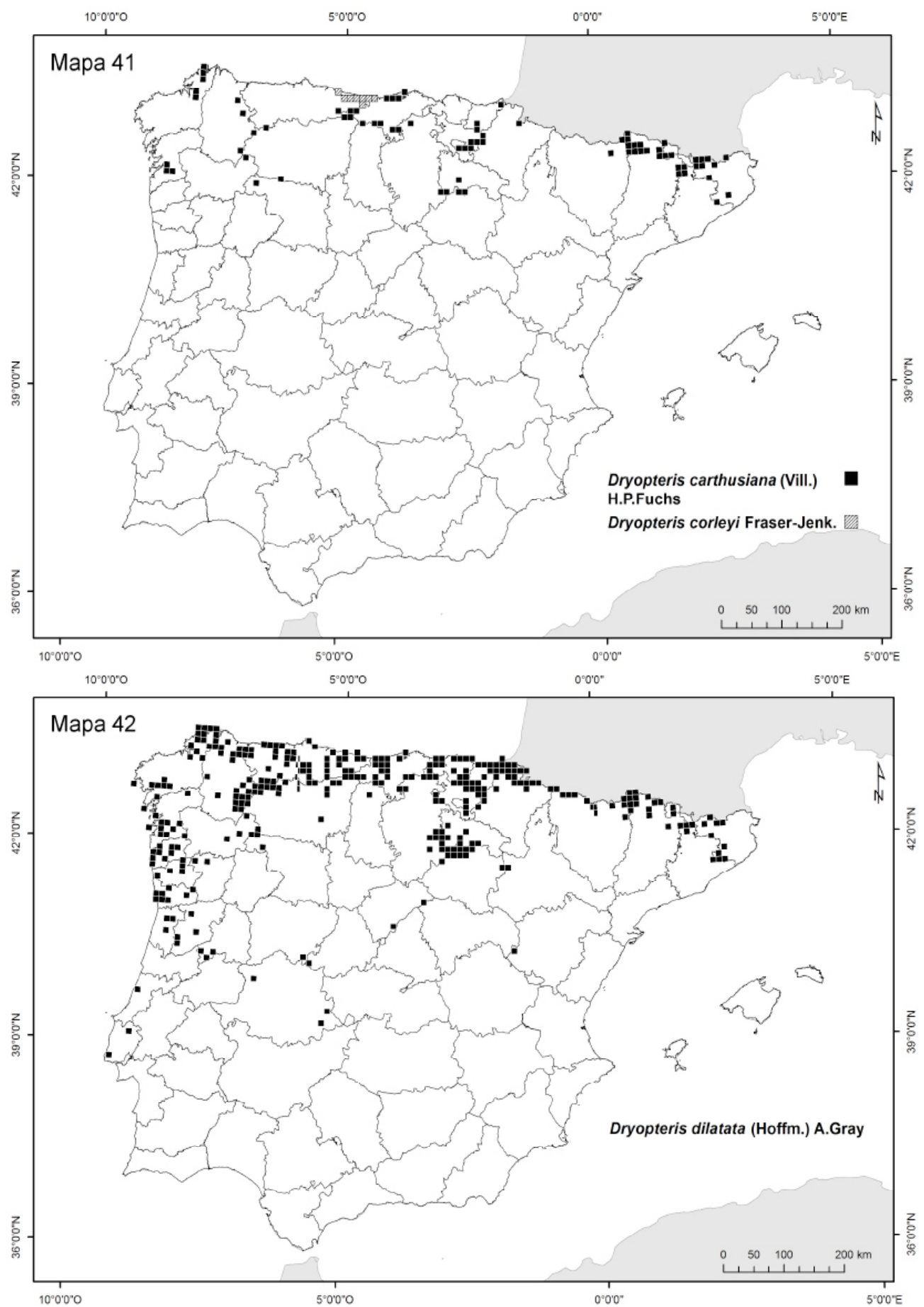

Figura 2. Atlas pteridológico. Mapas 41 y 42. 

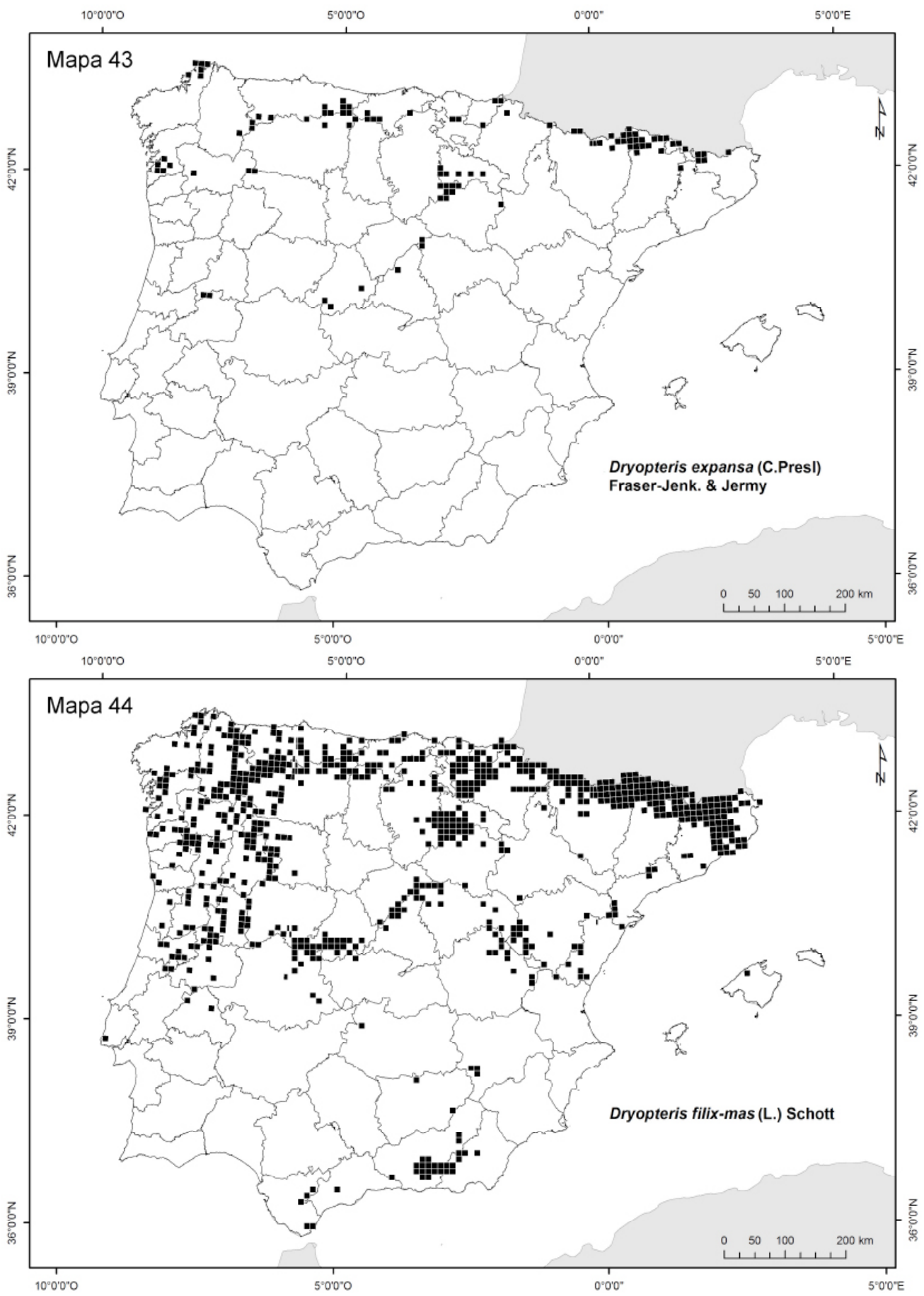

Figura 2. Atlas pteridológico. Mapas 43 y 44. 

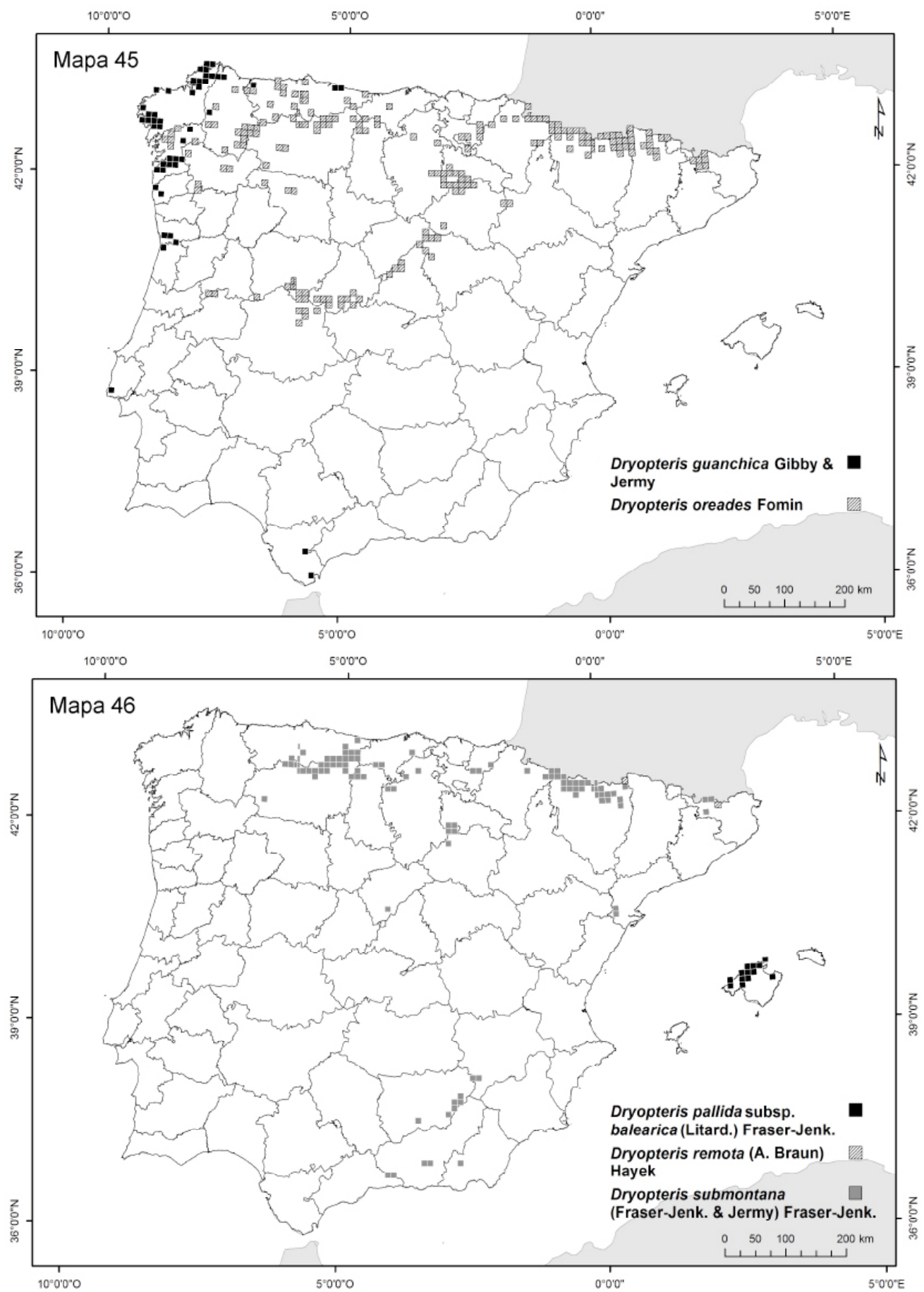

Figura 2. Atlas pteridológico. Mapas 45 y 46. 

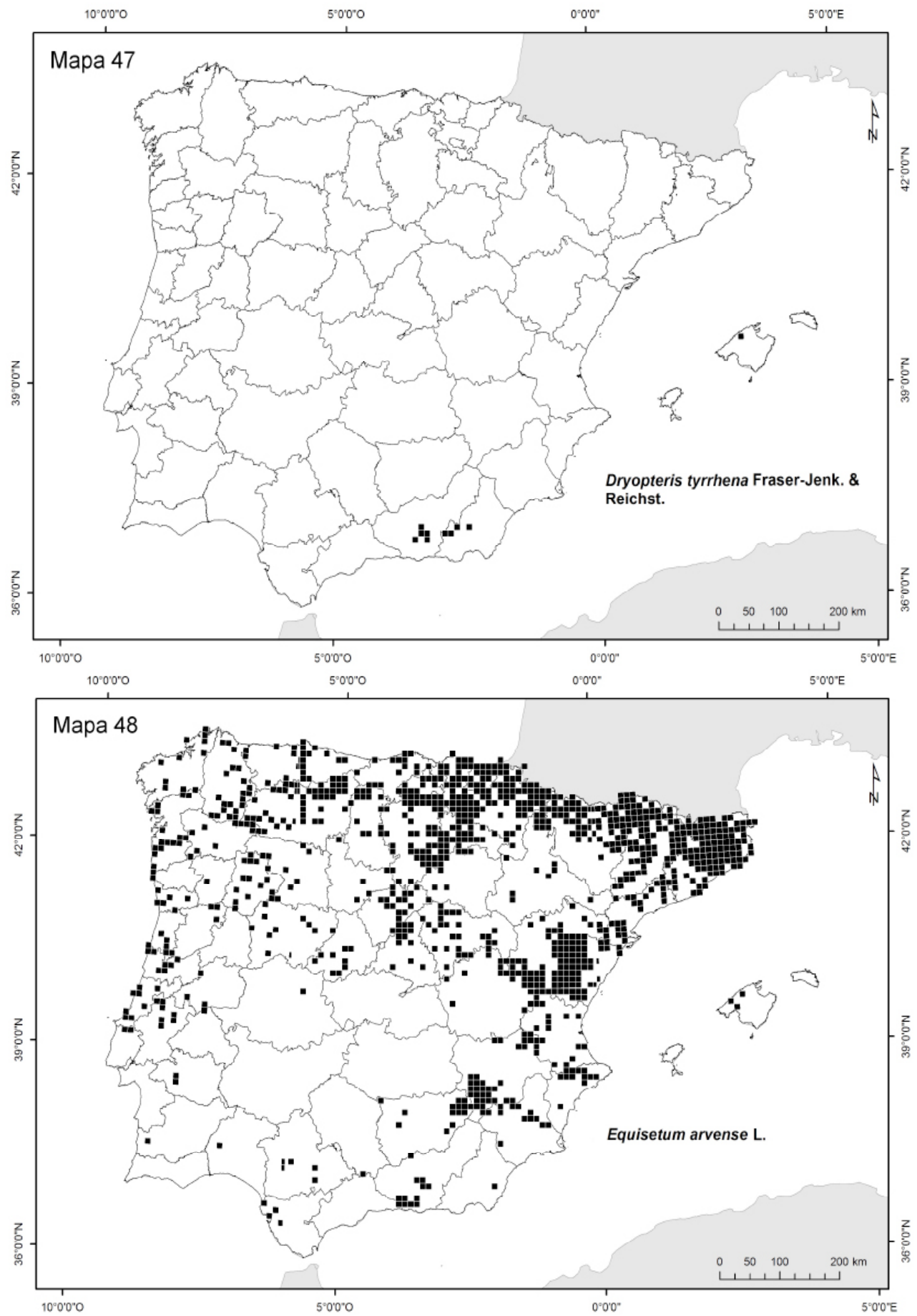

Figura 2. Atlas pteridológico. Mapas 47 y 48. 

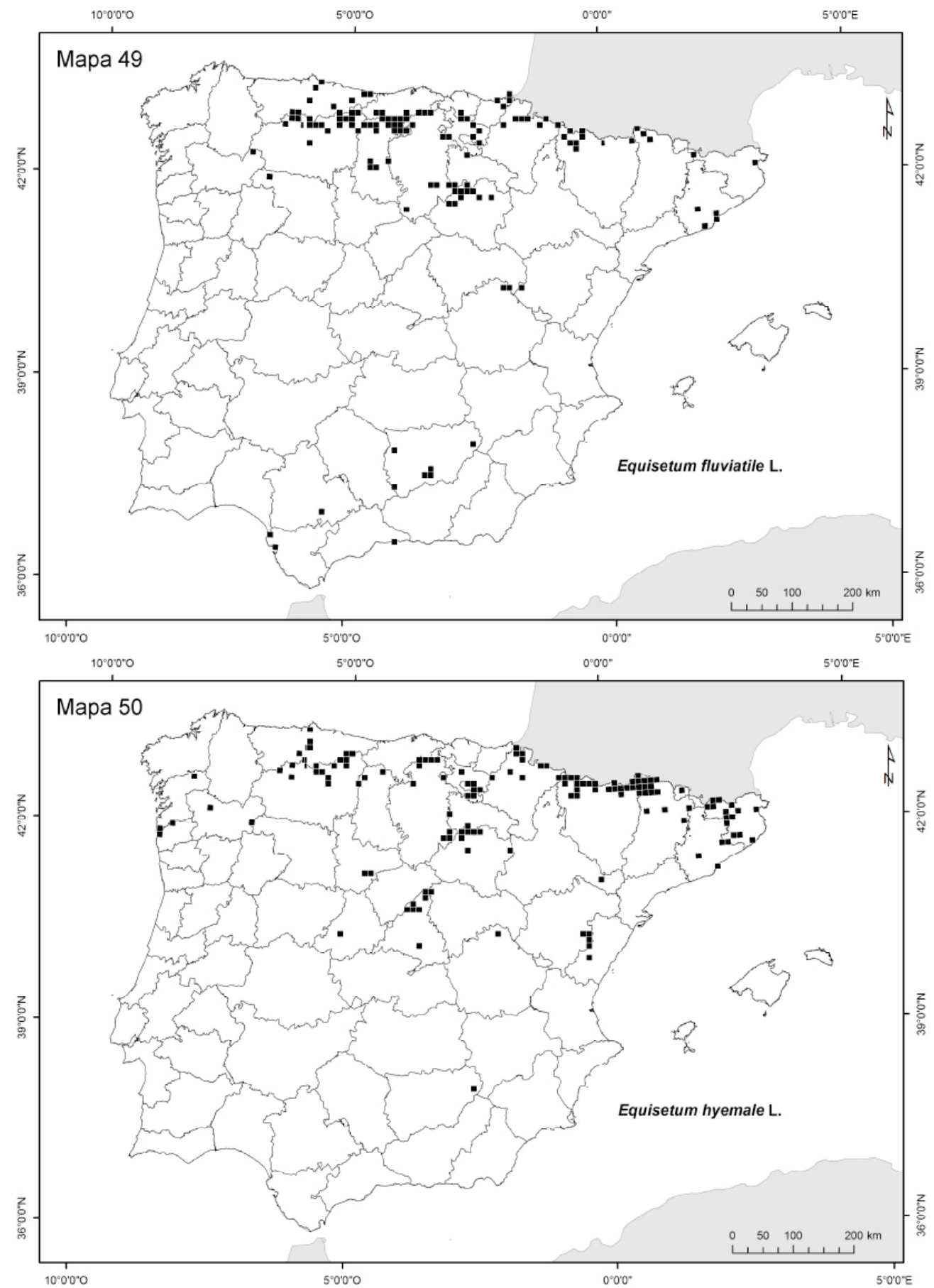

Figura 2. Atlas pteridológico. Mapas 49 y 50. 

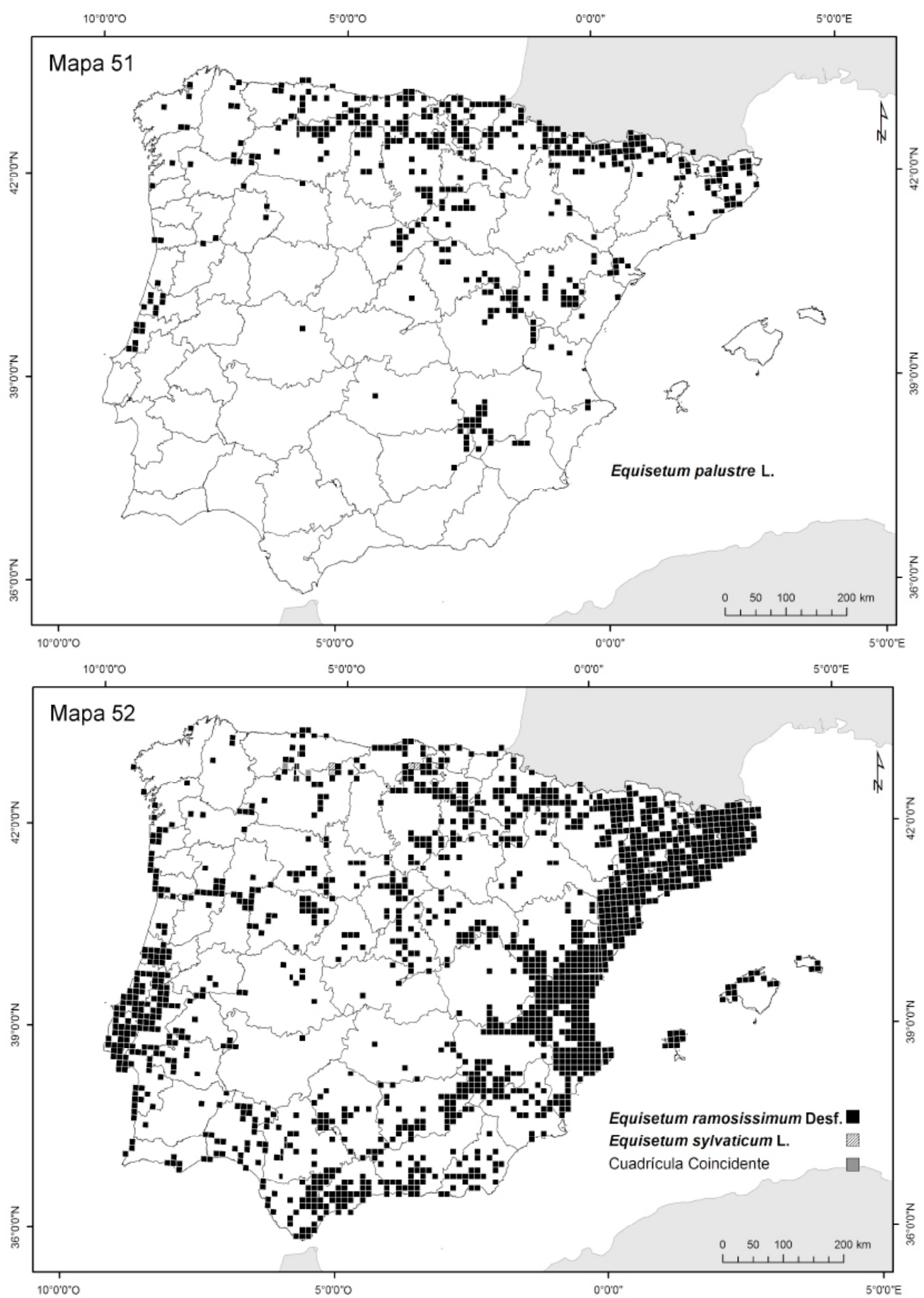

Figura 2. Atlas pteridológico. Mapas 51 y 52. 

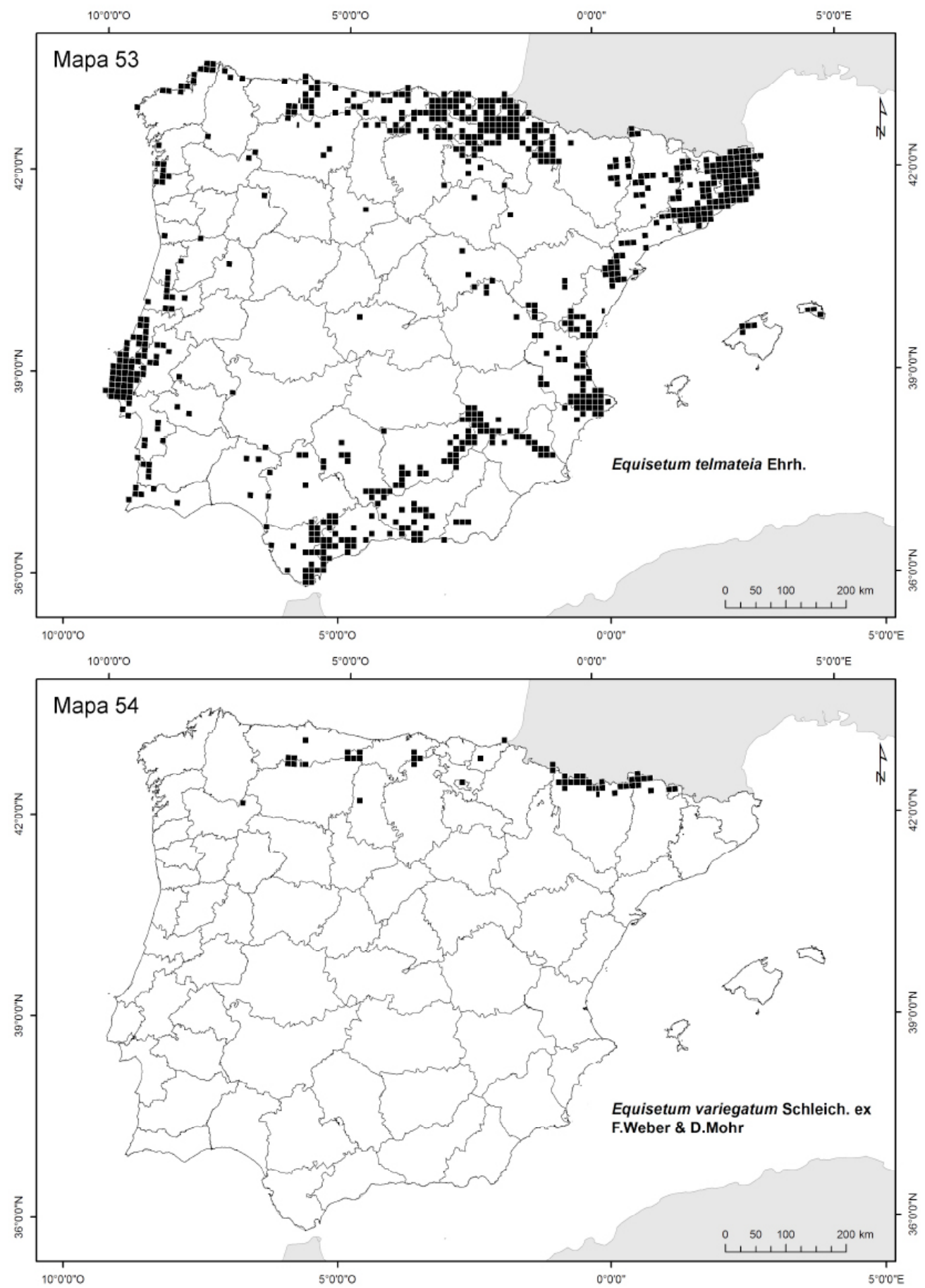

Figura 2. Atlas pteridológico. Mapas 53 y 54. 

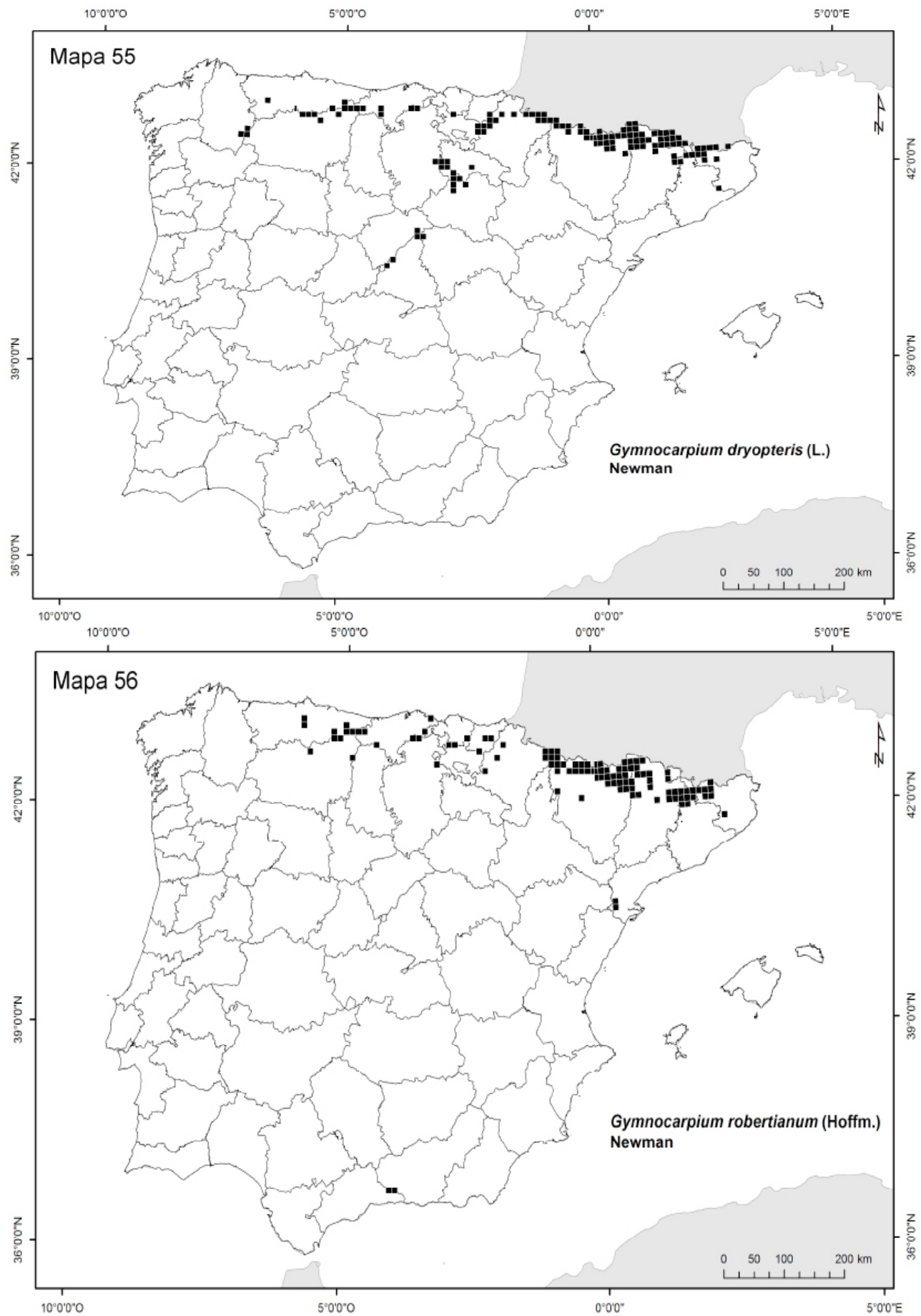

Figura 2. Atlas pteridológico. Mapas 55 y 56. 

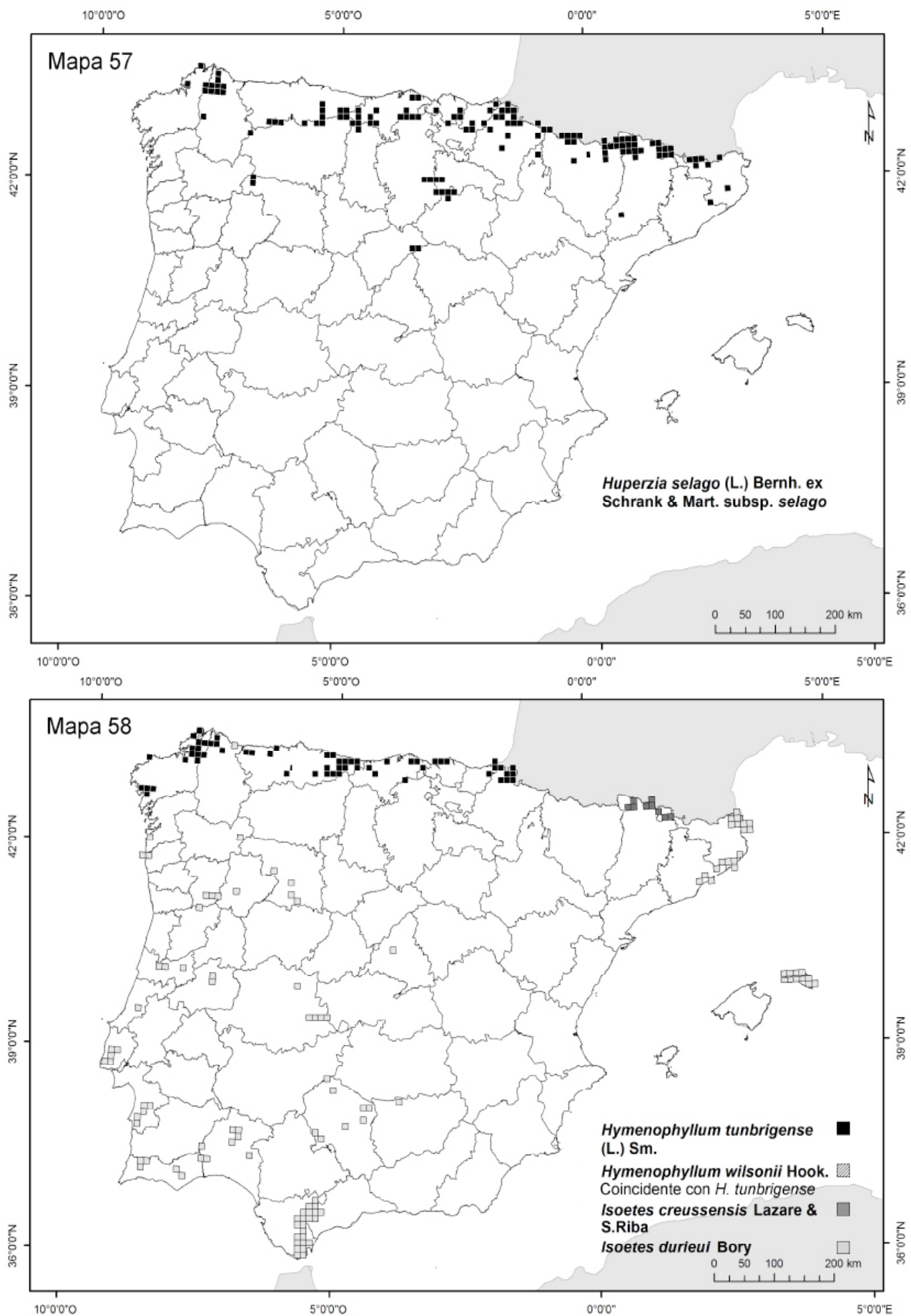

Figura 2. Atlas pteridológico. Mapas 57 y 58. 

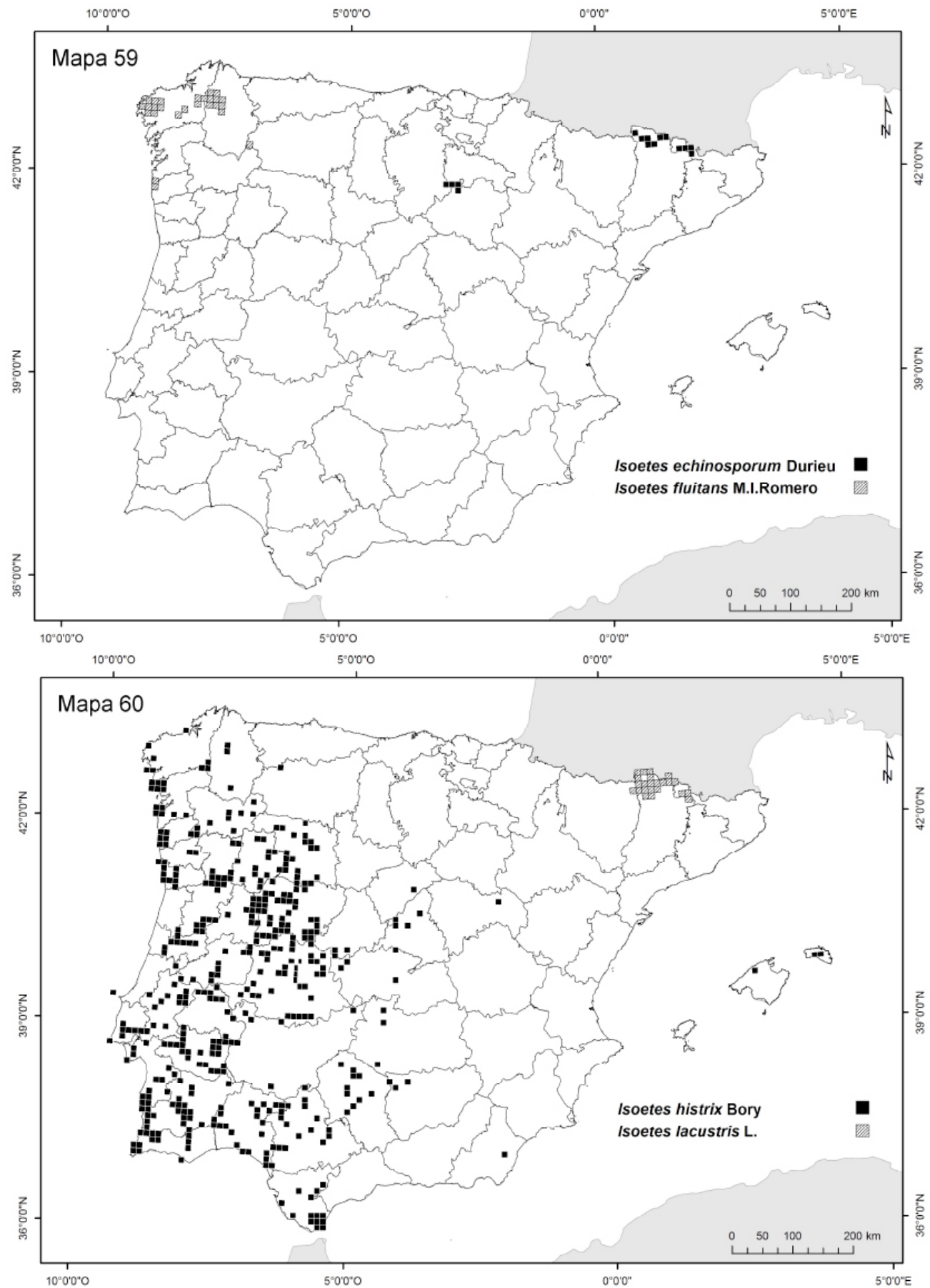

Figura 2. Atlas pteridológico. Mapas 59 y 60. 

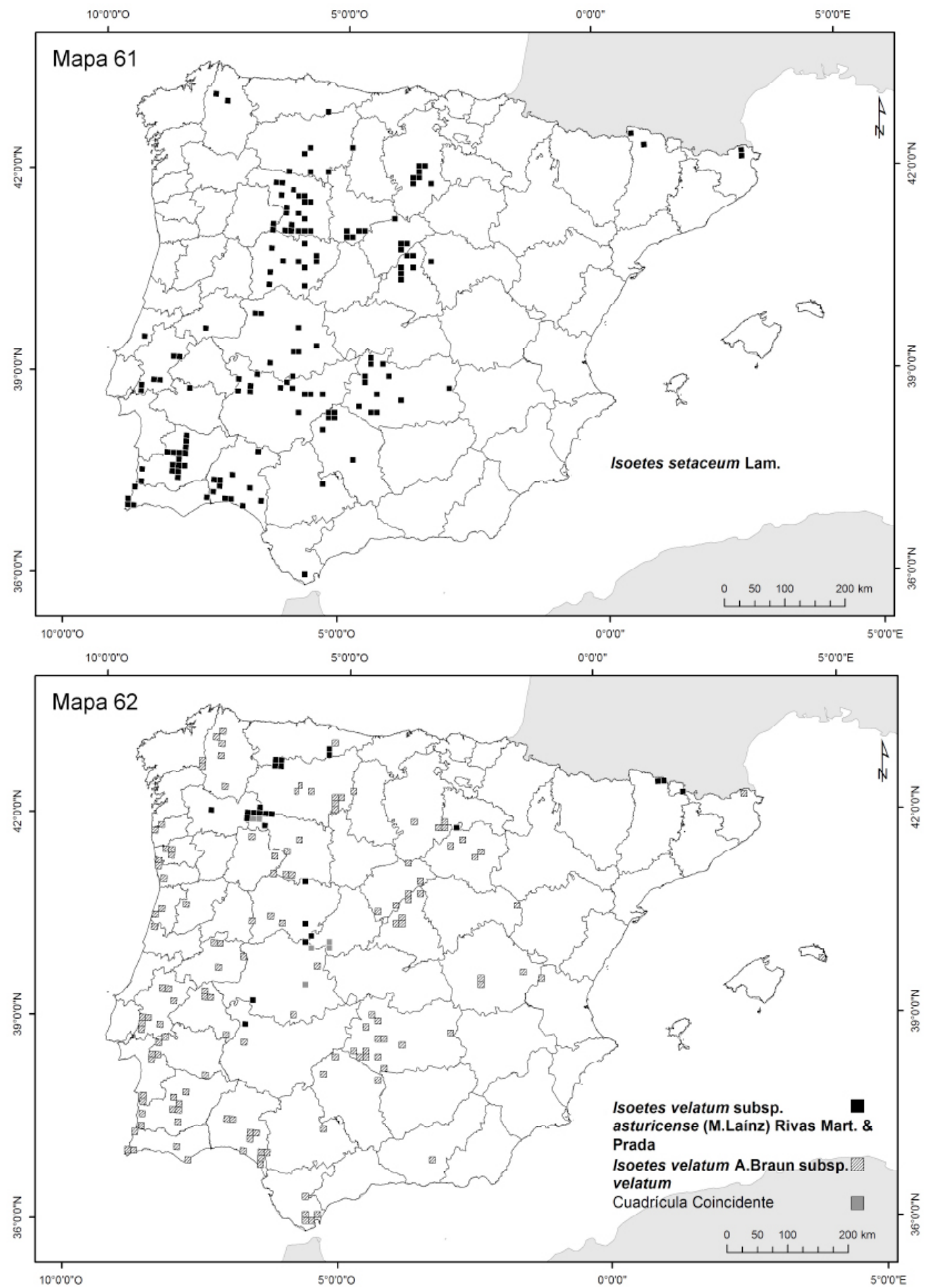

Figura 2. Atlas pteridológico. Mapas 61 y 62. 

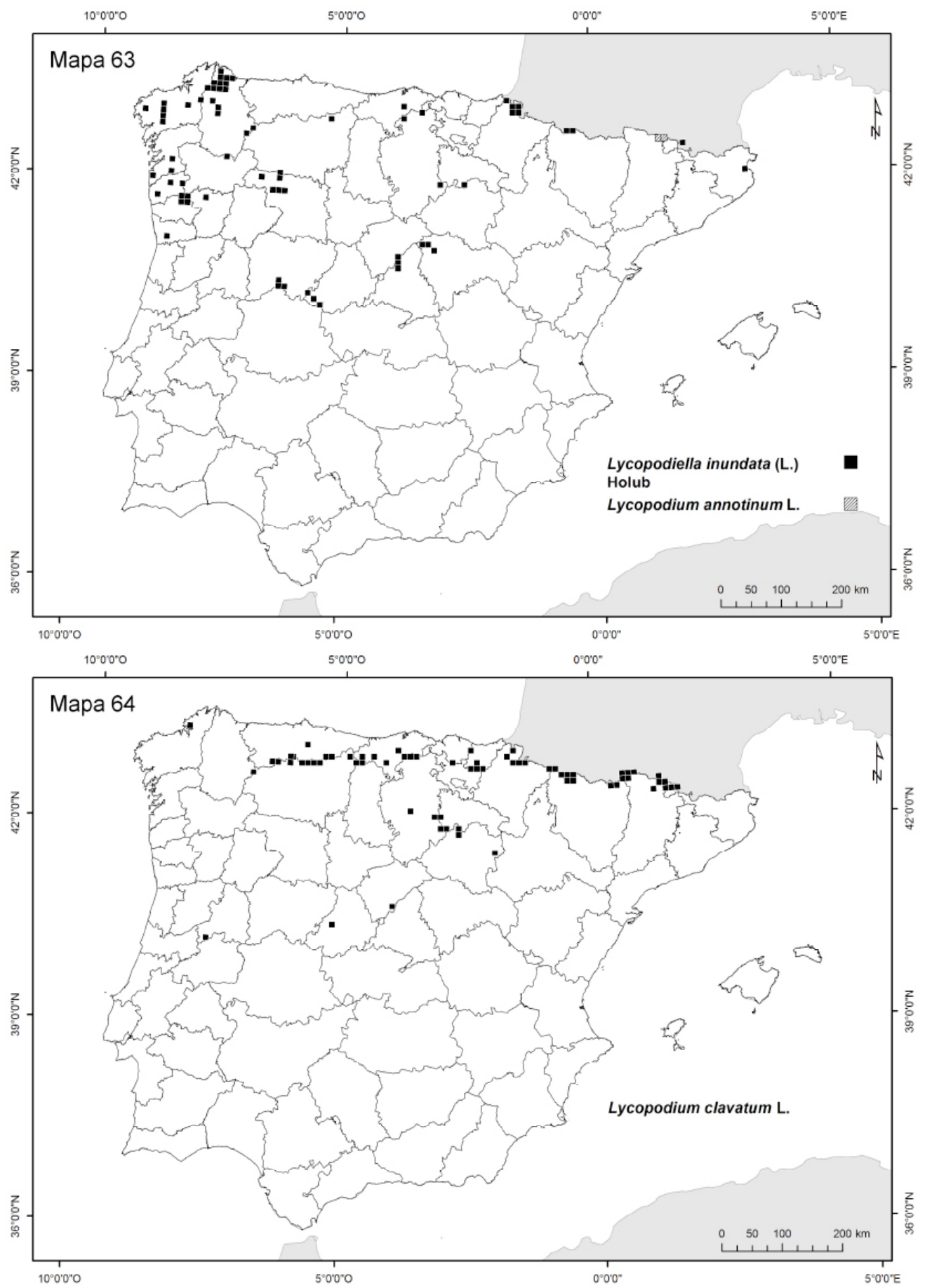

Figura 2. Atlas pteridológico. Mapas 63 y 64. 

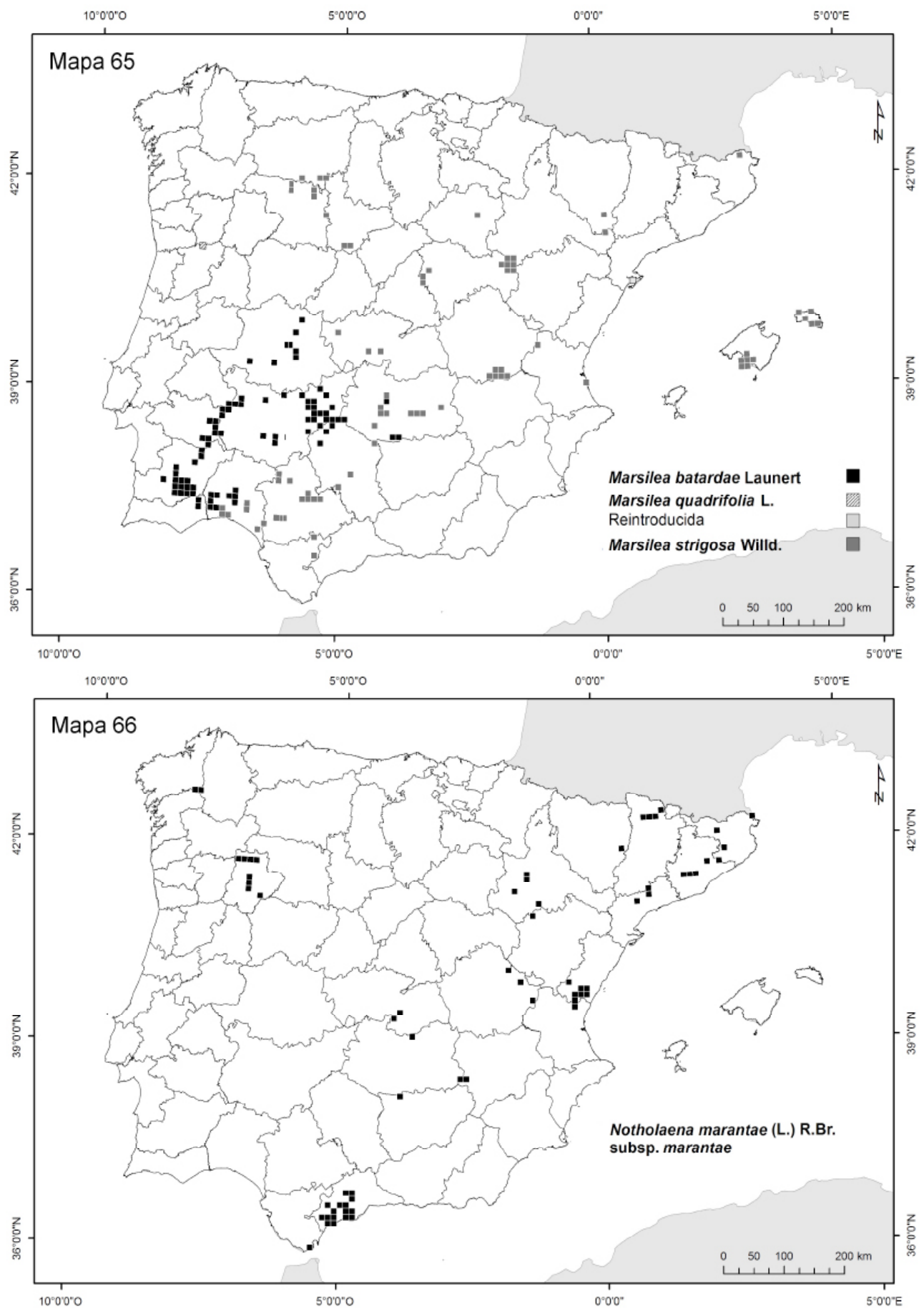

Figura 2. Atlas pteridológico. Mapas 65 y 66. 

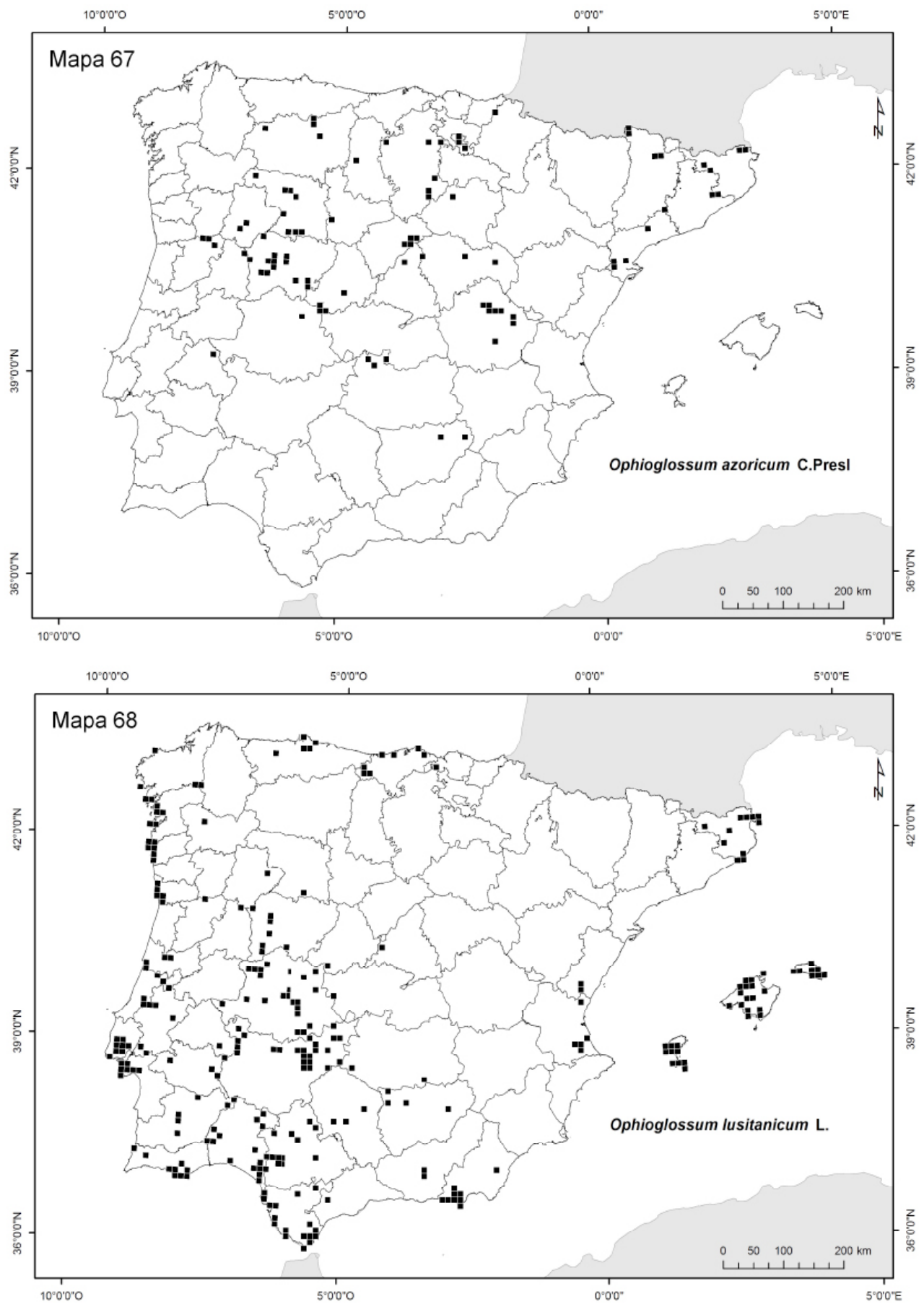

Figura 2. Atlas pteridológico. Mapas 67 y 68 . 

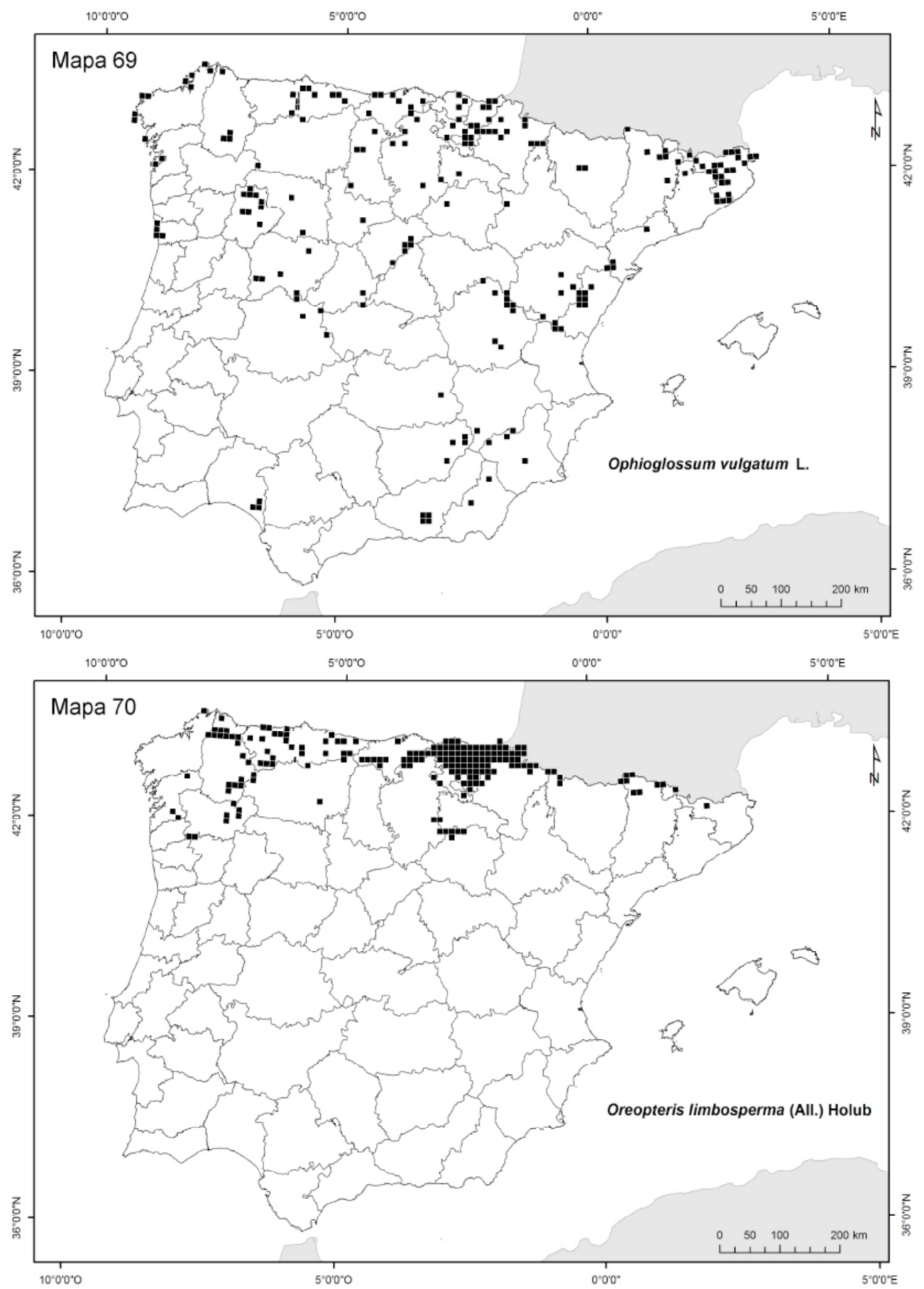

Figura 2. Atlas pteridológico. Mapas 69 y 70. 

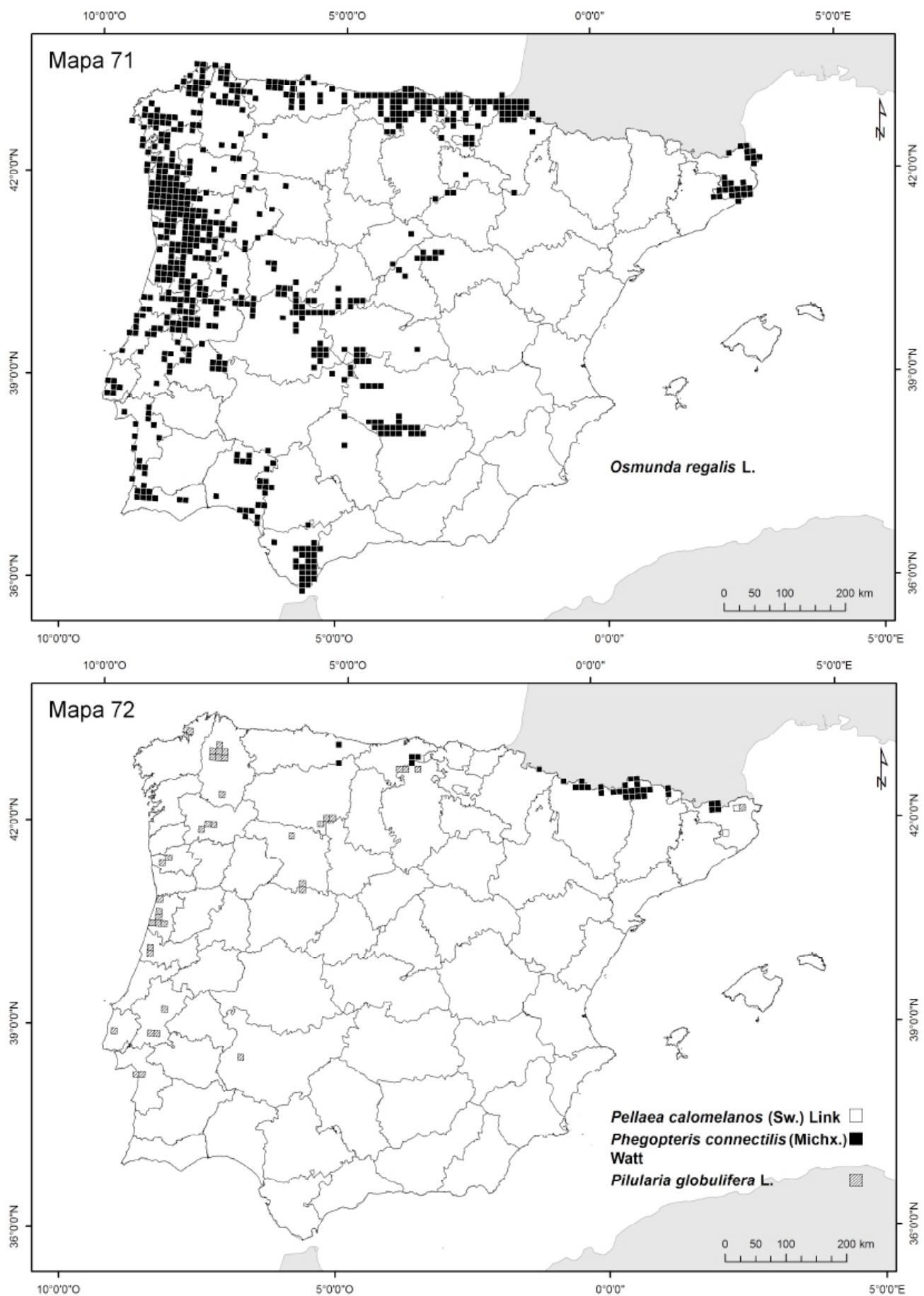

Figura 2. Atlas pteridológico. Mapas 71 y 72. 

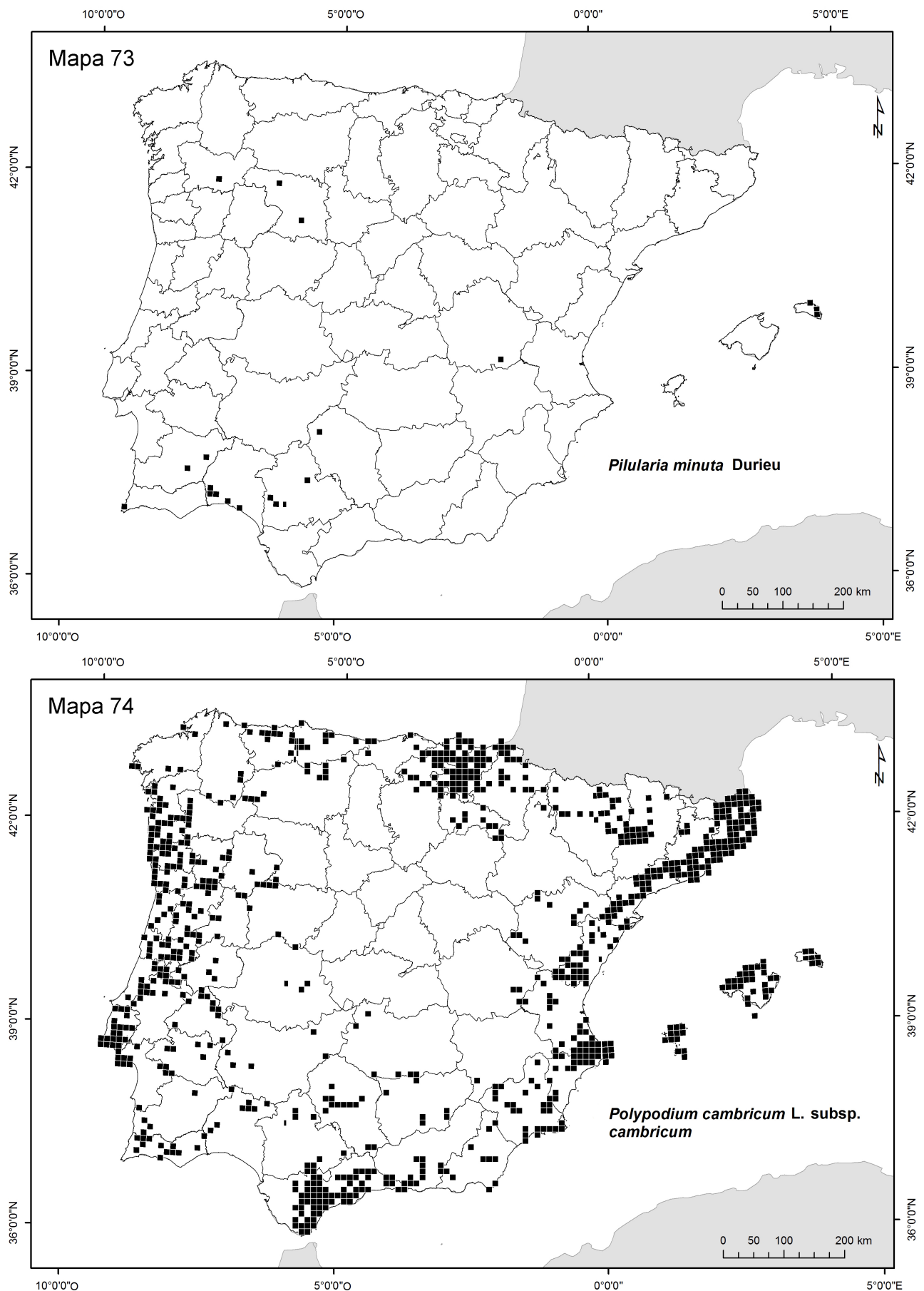

Figura 2. Atlas pteridológico. Mapas 73 y 74. 

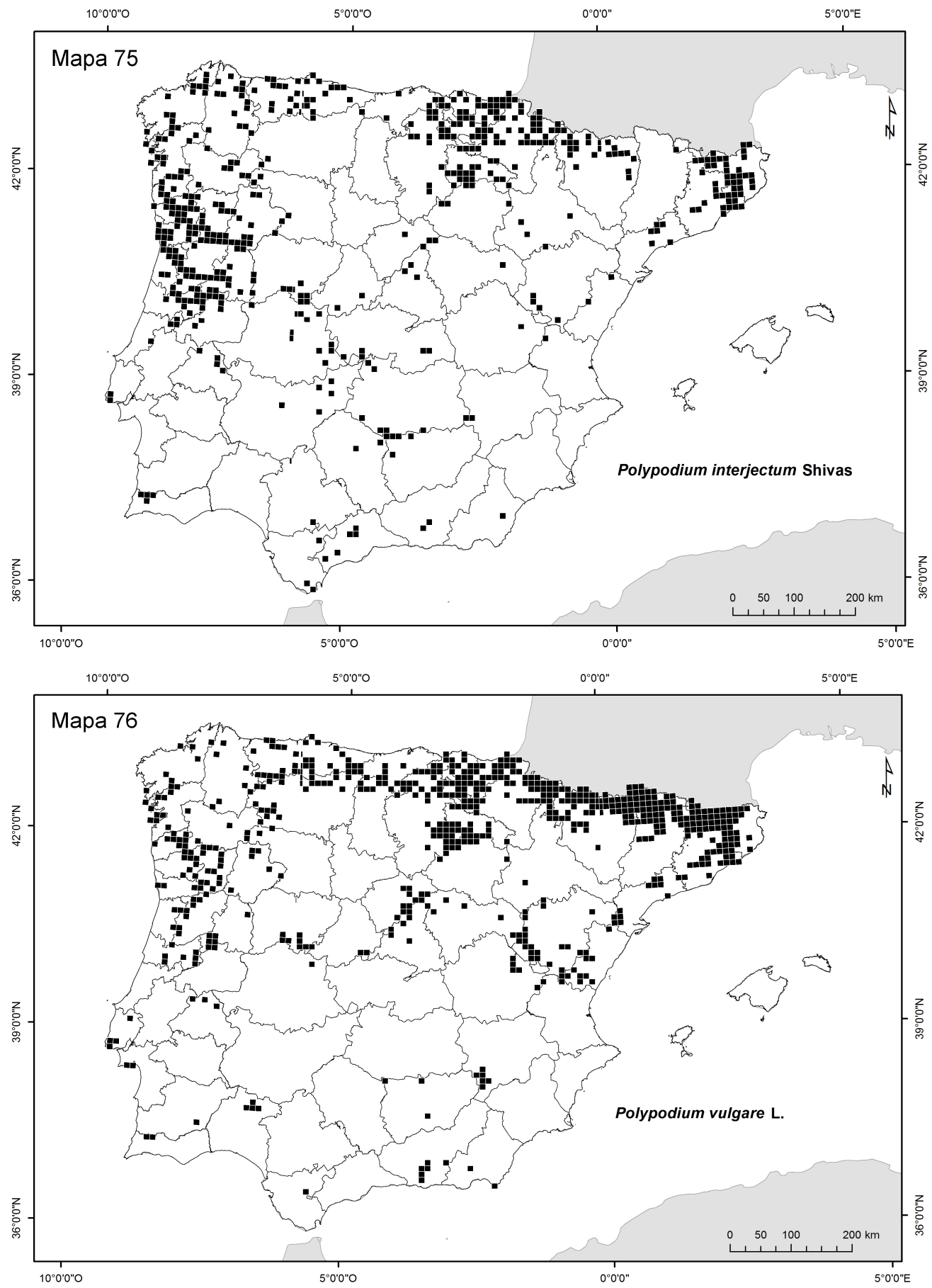

Figura 2. Atlas pteridológico. Mapas 75 y 76. 

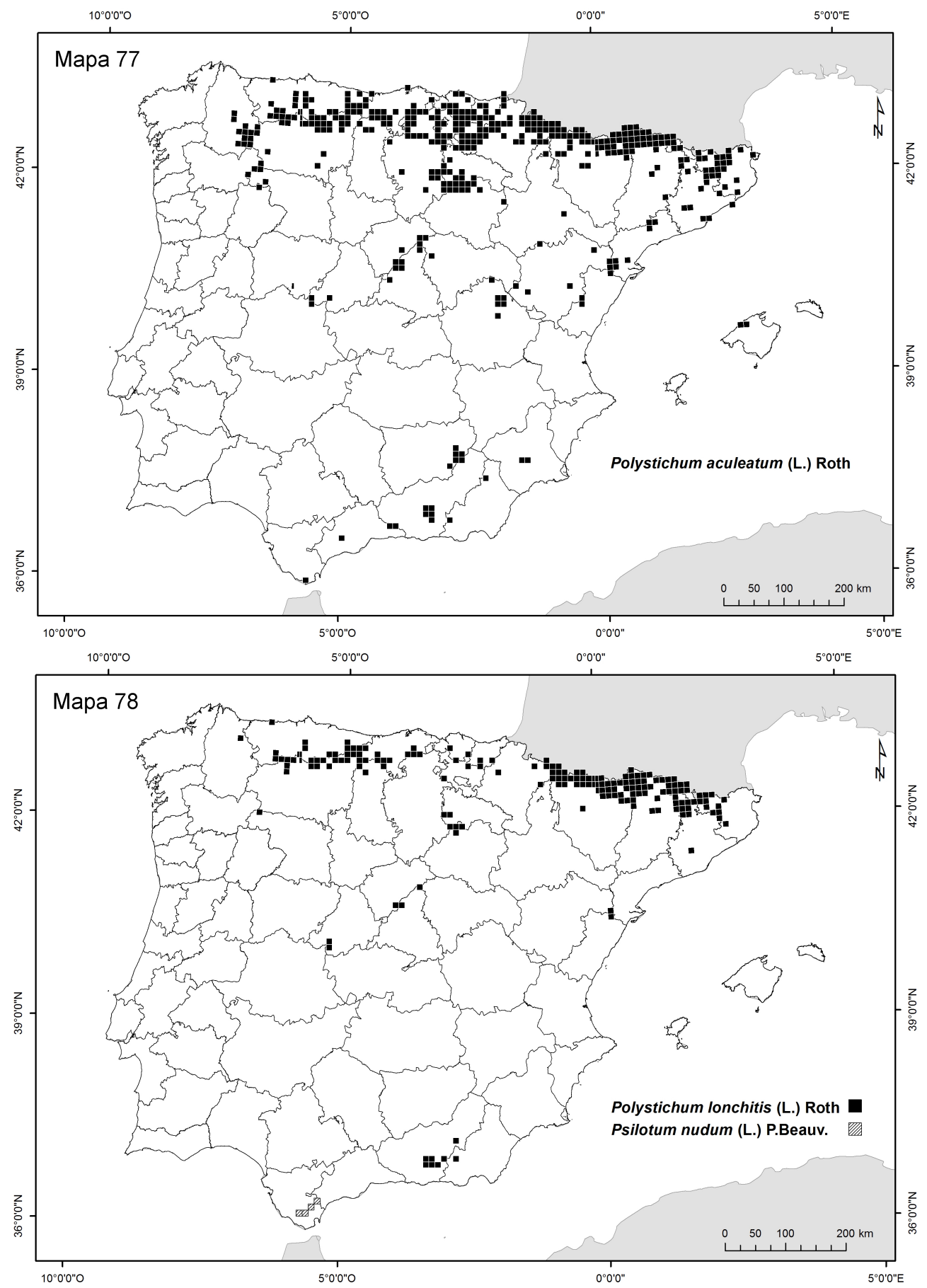

Figura 2. Atlas pteridológico. Mapas 77 y 78. 

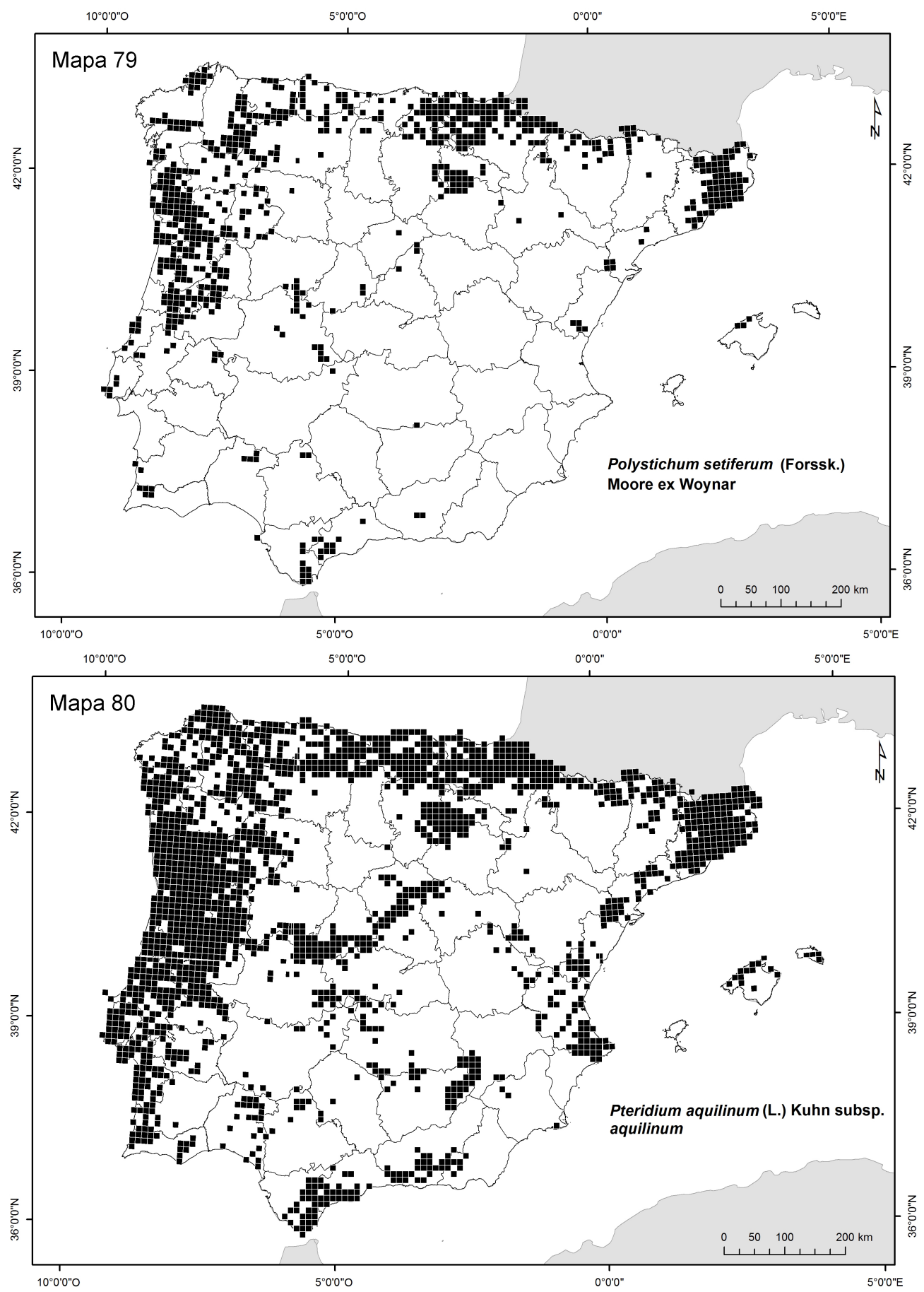

Figura 2. Atlas pteridológico. Mapas 79 y 80. 

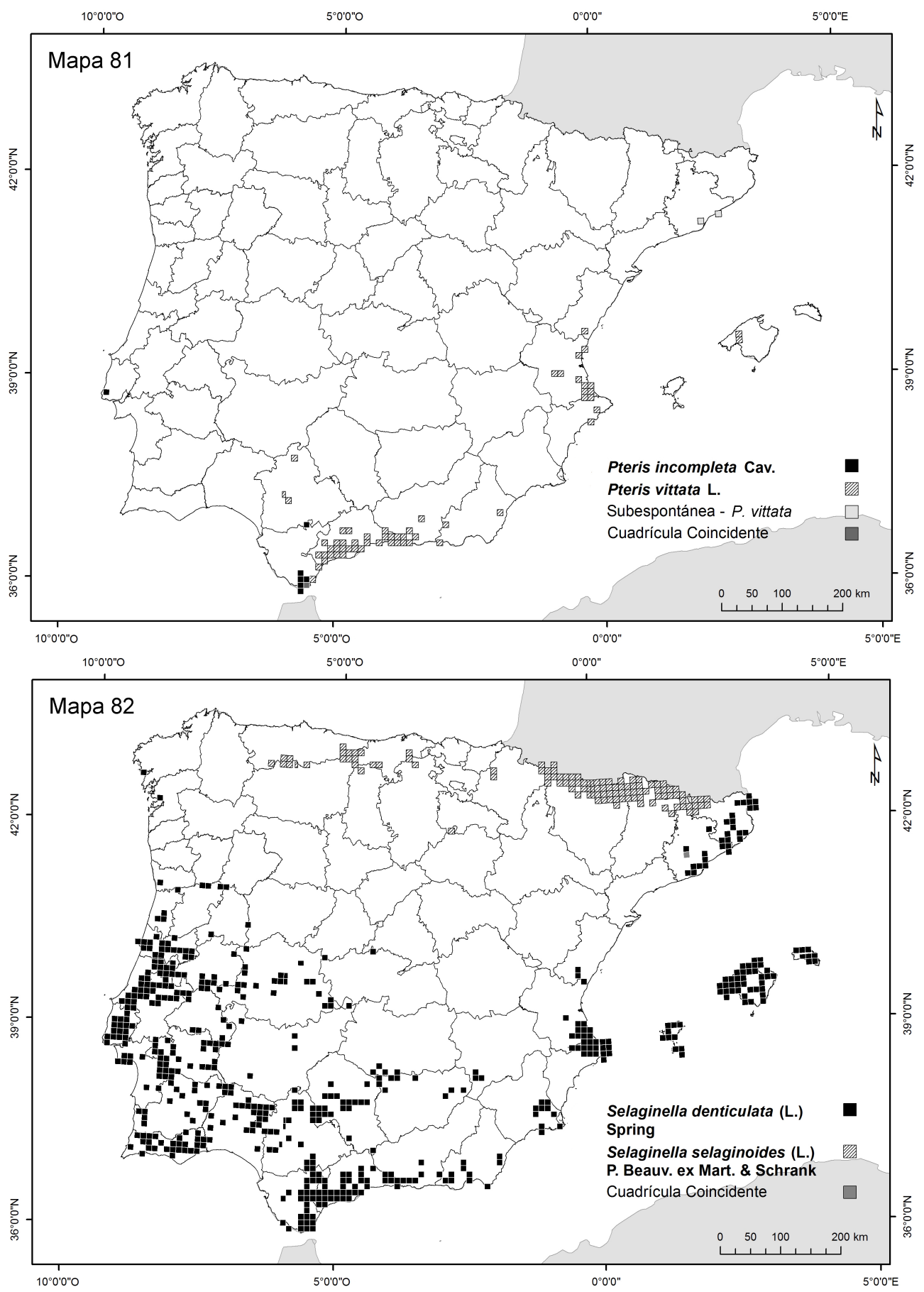

Figura 2. Atlas pteridológico. Mapas 81 y 82 . 

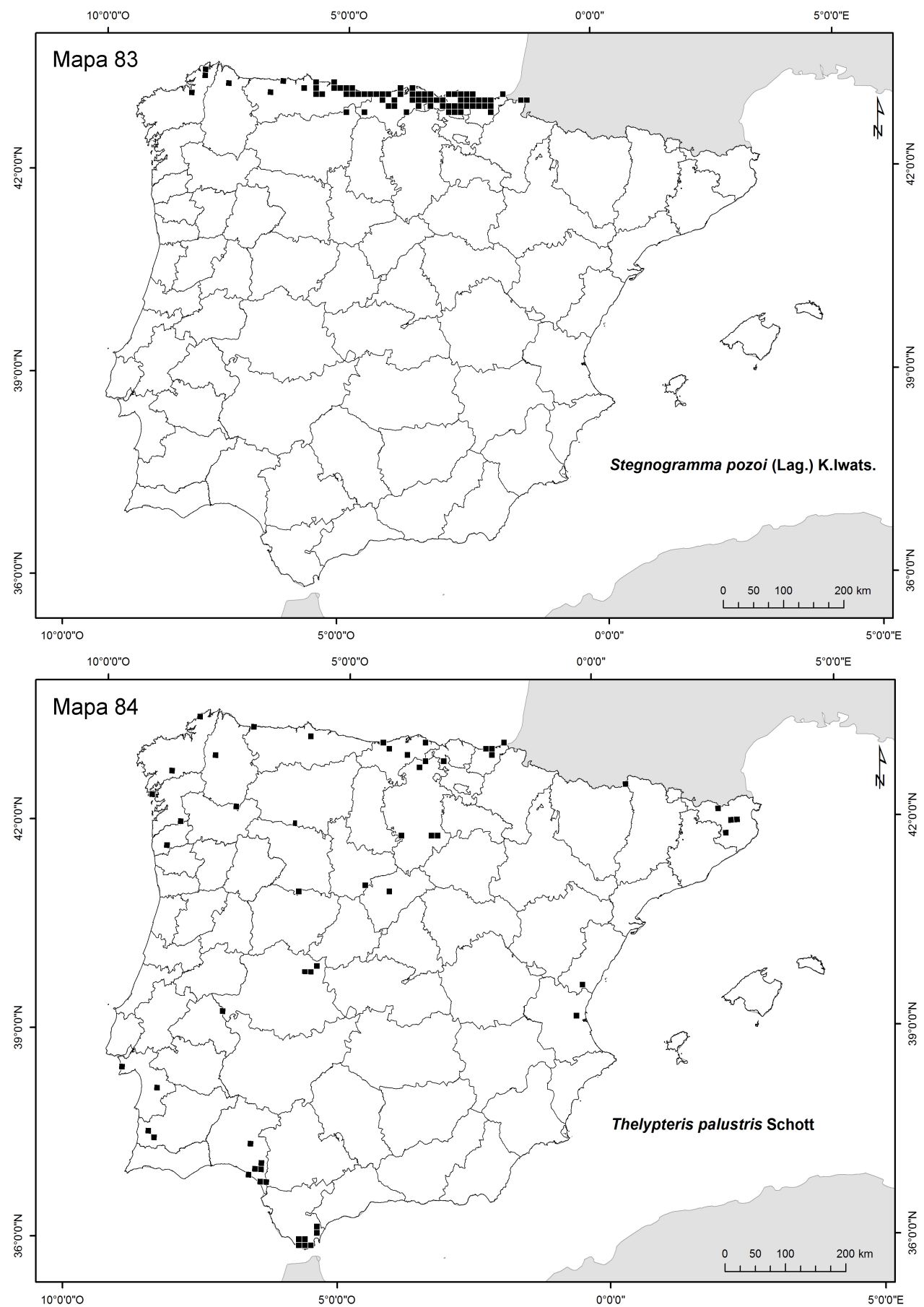

Figura 2. Atlas pteridológico. Mapas 83 y 84 . 

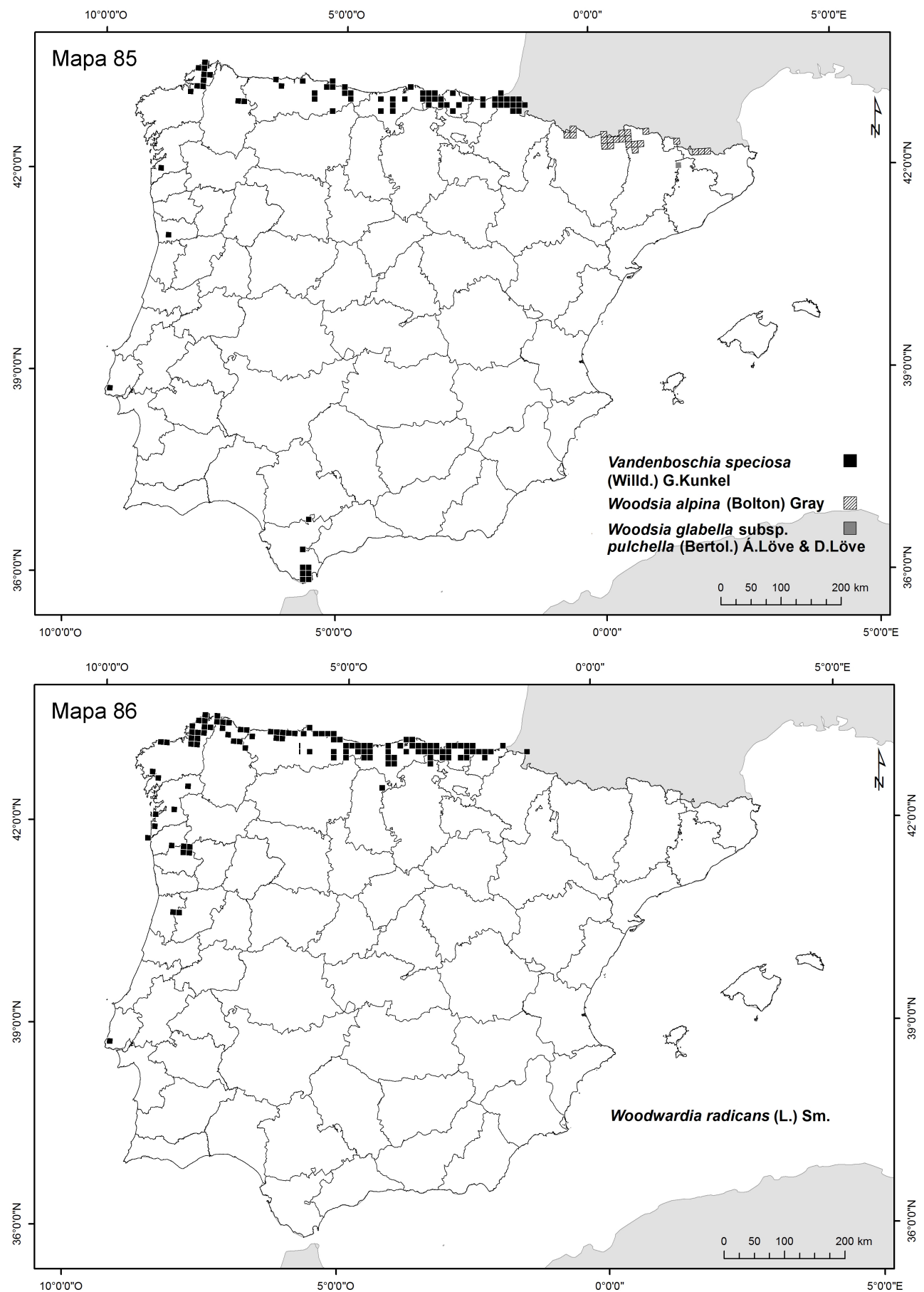

Figura 2. Atlas pteridológico. Mapas 85 y 86 . 

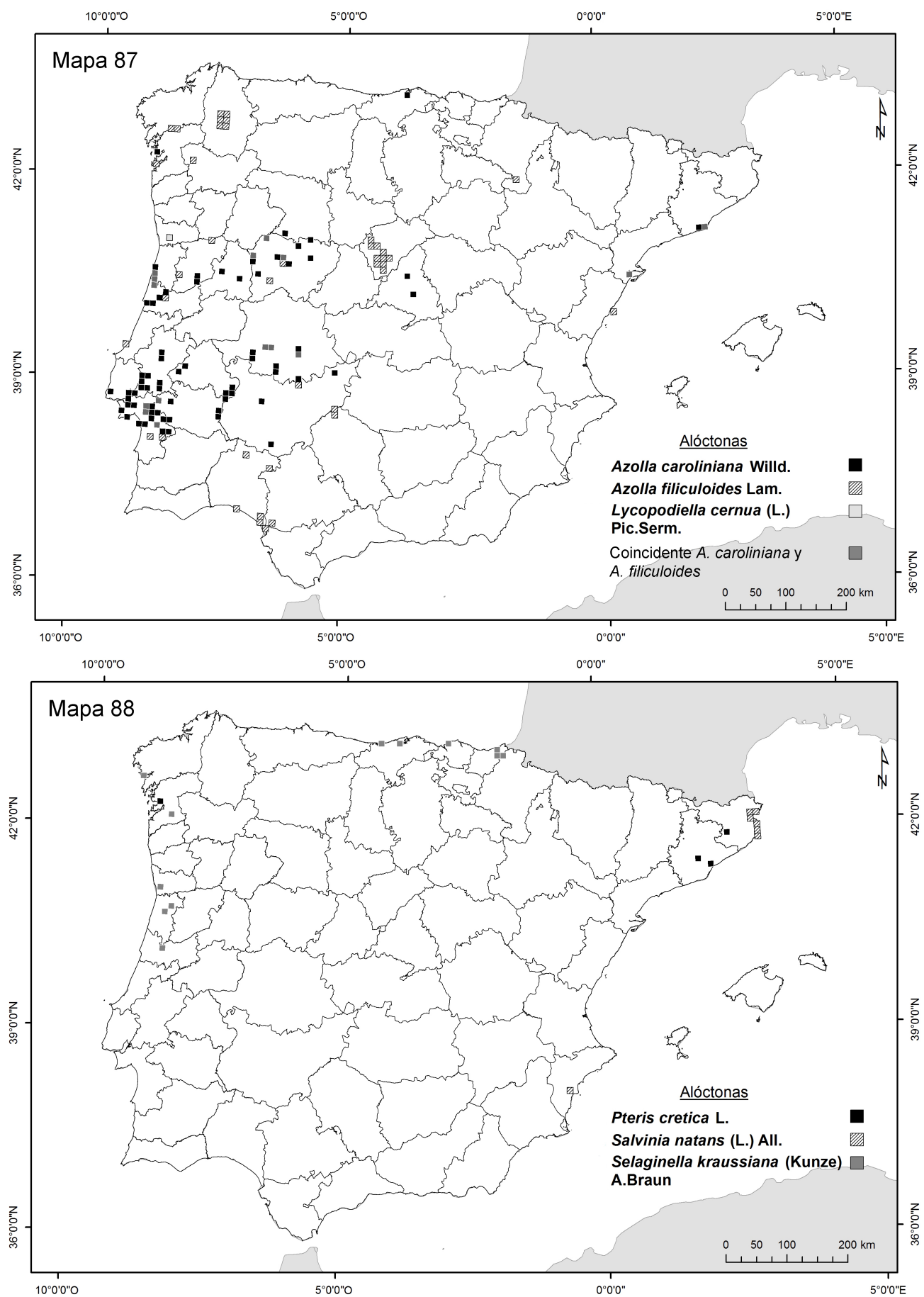

Figura 2. Atlas pteridológico. Mapas 87 y 88 . 